\title{
molecules
}

ISSN 1420-3049

www.mdpi.com/journal/molecules

Article

\section{Synthesis and Biological Evaluation of 3-Benzisoxazolyl-4-indolylmaleimides as Potent, Selective Inhibitors of Glycogen Synthase Kinase-3及}

\section{Qing Ye ${ }^{1}$, Meng Li ${ }^{1}$, Yubo Zhou ${ }^{2}$, Tao Pang ${ }^{2}$, Lei Xu ${ }^{2}$, Jiayi Cao ${ }^{2}$, Liang Han ${ }^{1}$, Yujin Li ${ }^{1}$,} Weisi Wang ${ }^{3}$, Jianrong Gao ${ }^{1, *}$ and $\mathrm{Jia} \mathrm{Li}^{2, *}$

1 State Key Laboratory Breeding Base of Green Chemistry-Synthesis Technology,

Zhejiang University of Technology, Hangzhou 310032, Zhejiang, China;

E-Mails: yeqing1975@yeah.net (Q.Y.); limeng71085110@126.com (M.L.);

hanliang@zjut.edu.cn (L.H.); lyjzjut@zjut.edu.cn (Y.L.)

2 The National Center for Drug Screening, Shanghai 201203, China;

E-Mails: ybzhou@mail.shcnc.ac.cn (Y.Z.); tyne_pang@hotmail.com (T.P.);

1xu@mail.shcnc.ac.cn (L.X.); jycao@mail.shcnc.ac.cn (J.C.)

3 ZJU-ENS Joint Laboratory of Medicinal Chemistry, College of Pharmaceutical Sciences,

Zhejiang University, Hangzhou 310058, Zhejiang, China, E-Mail: pipilu1985@zju.edu.cn

* Authors to whom correspondence should be addressed; E-Mails: gdgjr@zjut.edu.cn (J.G.);

jli@mail.shcnc.ac.cn (J.L.); Tel./Fax: +86-571-8832-0891 (J.G.).

Received: 21 March 2013; in revised form: 2 May 2013 / Accepted: 7 May 2013/

Published: 13 May 2013

\begin{abstract}
A series of novel 3-benzisoxazolyl-4-indolyl-maleimides were synthesized and evaluated for their GSK-3 $\beta$ inhibitory activity. Most compounds exhibited high inhibitory potency towards GSK-3 $\beta$. Among them, compound $7 \mathbf{j}$ with an $\mathrm{IC}_{50}$ value of $0.73 \mathrm{nM}$ was the most promising GSK-3 $\beta$ inhibitor. Preliminary structure-activity relationships were examined and showed that different substituents on the indole ring and $\mathrm{N}^{1}$-position of the indole ring had varying degrees of influence on the GSK-3 $\beta$ inhibitory potency. Compounds 7c, 7f, $\mathbf{7 j}-\mathbf{I}$ and $\mathbf{7 0}-\mathbf{q}$ could obviously reduce A $\beta$-induced Tau hyperphosphorylation by inhibiting GSK-3 $\beta$ in a cell-based functional assay.
\end{abstract}

Keywords: 3-benzisoxazolyl-4-indolylmaleimides; synthesis; GSK-3 $\beta$; biological activity; docking; SAR 


\section{Introduction}

Glycogen synthase kinase-3 (GSK-3) is a serine/threonine protein kinase which was identified in the late 1970s. Mammalian GSK-3 exists as two isoforms, GSK-3 $\alpha$ and GSK-3 $\beta$ which share high homology at the catalytic domain but significantly differ in their $\mathrm{N}$-terminal domain $(84 \%$ overall and $98 \%$ in catalytic domain). Both isomers ubiquitously exist in cells and tissues and have similar biochemical properties [1-4]. GSK-3 $\beta$ plays a critical role in glycogen metabolism, embryogenesis, mitotic regulation, inflammation and neuroplasticity [5-8]. Inhibition of GSK-3 $\beta$ may provide therapy approach for several diseases such as cancer, type 2 diabetes, chronic inflammatory processes, stroke, bipolar disorders and Alzheimer's disease [9-13]. Accordingly, searching for novel and selective GSK-3 $\beta$ inhibitors is a very active area in both academic centers and pharmaceutical companies.

Staurosporine, a microbial alkaloid, was identified as a potent but nonselective GSK-3 $\beta$ inhibitor. Various bisindolylmaleimides such as GF 109203X and Ro 31-8220 have also been developed as potent GSK-3 $\beta$ inhibitors based on staurosporine (Figure 1) [14-16]. However, most of these bisindolylmaleimides are not suitable for the treatment of diseases such as diabetes and Alzheimer's disease due to their toxicity, poor solubility and low selectivity, especially against PKC family $[17,18]$. The replacement of one indole with other heteroaryl groups resulted in a series of monoindolylmaleimides such as 4-azaindolyl-indolyl-maleimides, benzofuranyl-indolyl-maleimides and imidazo[1,2-a]pyridinyl-indolyl-maleimides (Figure 1), which showed potent and selective GSK-3 $\beta$ inhibitory activities [19-21].

Figure 1. GSK-3 $\beta$ inhibitors.
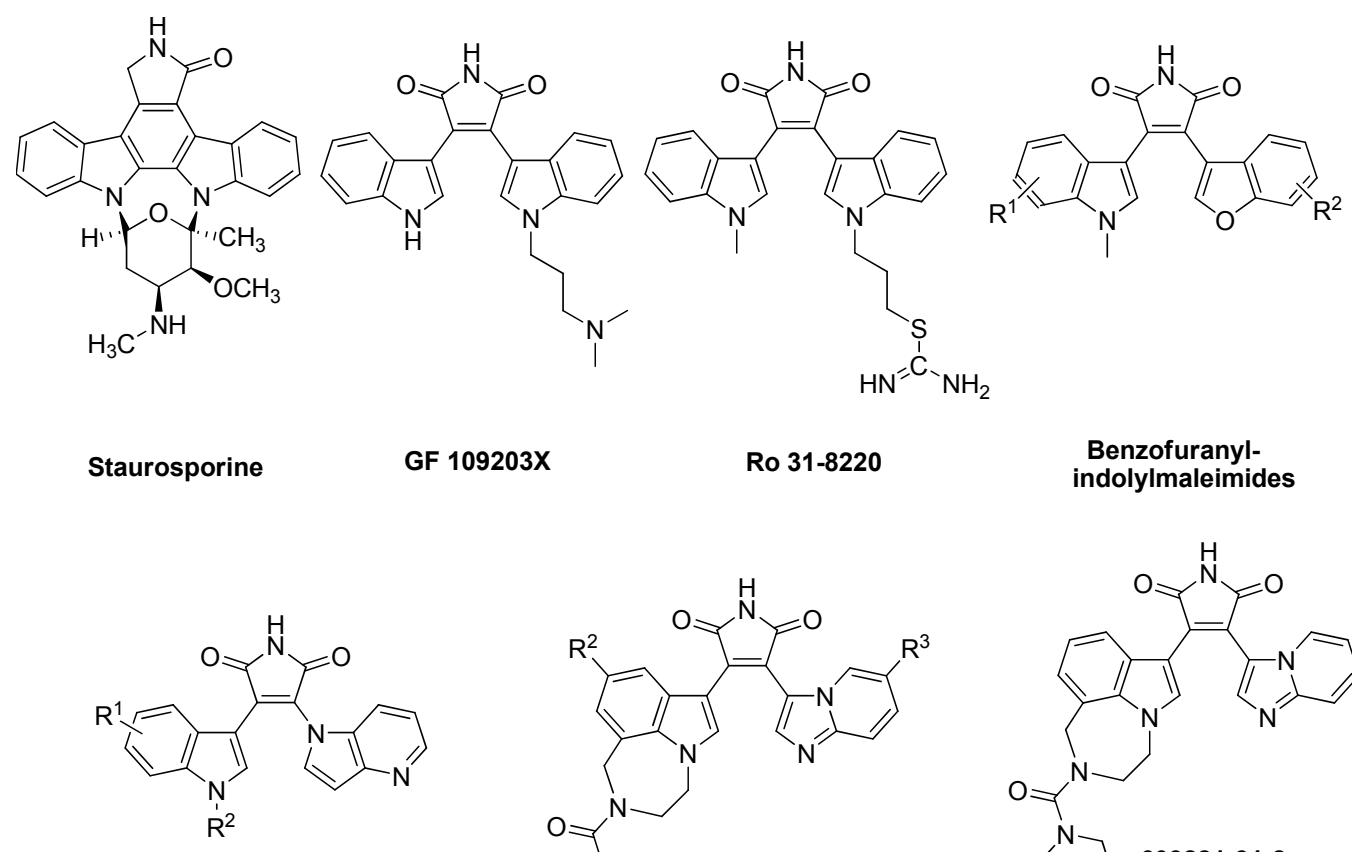

GF 109203X

Ro $31-8220$

Benzofuranyl-
indolylmaleimides
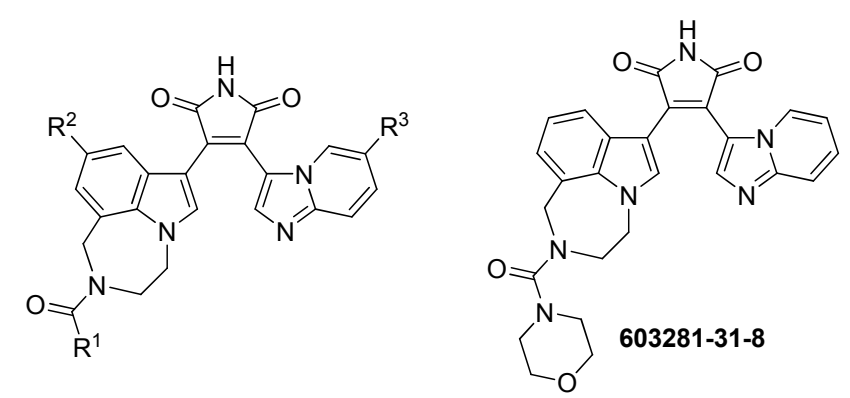

4-Azaindolyl-indolylmaleimides

Imidazo[1,2-a]pyridinyl-indolylmaleimides

Among them, GSK-3 $\beta$ inhibitor 603281-31-8 developed by Eli Lilly \& Co had reached preclinical studies for the treatment of diabetes and was proved efficacy in ZDF rats [19]. In view of these facts 
and also as a part of our work on the development of potent and selective GSK-3 $\beta$ inhibitors, herein we report the synthesis and biological evaluation of a new series of 3-benzisoxazolyl-4-indolyl-maleimides as GSK-3 $\beta$ inhibitors. Their structure-activity relationship and in silico molecular modeling study are also discussed in this study.

\section{Results and Discussion}

\subsection{Chemistry}

The general synthetic approach to target compounds $\mathbf{7 a - q}$ is outlined in Scheme 1.

Scheme 1. Synthetic route to compounds $7 \mathbf{a}-\mathbf{q}$.

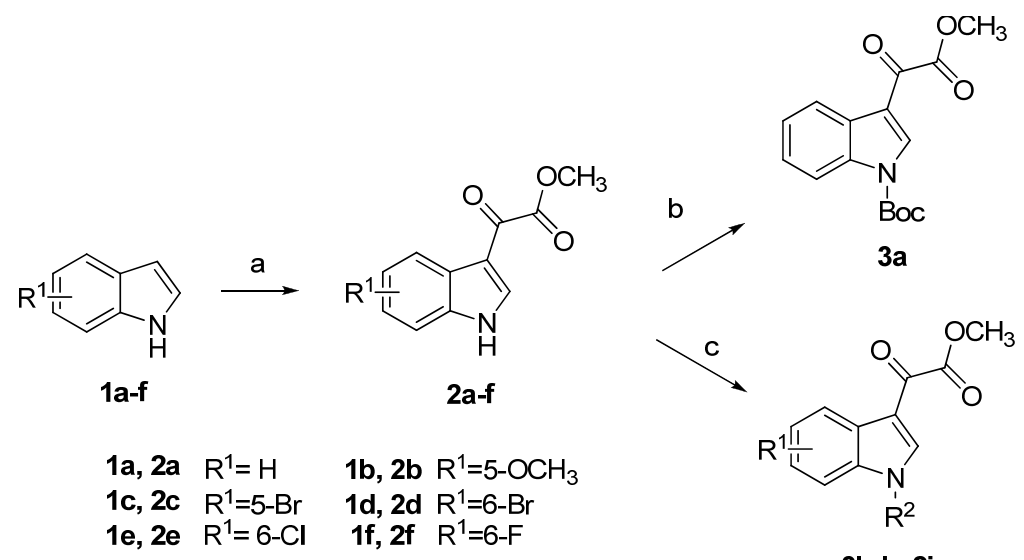

3b-h, 3j-q<smiles>COC(=O)C(=O)c1cn(CC2CCCCC2)c2ccccc12</smiles><smiles>[R]Nc1cc(C(=O)C(=O)OC)c2cc[R1]cc12</smiles>

3a-q<smiles>NC(=O)Cc1noc2ccccc12</smiles>

6<smiles>[R4]c1cc2ncc(C3=C(c4noc5ccccc45)C(=O)NC3=O)c-2cn1[R]</smiles>

$7 a-q$

7a $\quad \mathrm{R}^{1}=\mathrm{H}, \quad \mathrm{R}^{2}=\mathrm{H}$

3b, 7b $\quad R^{1}=5-\mathrm{OMe}, \mathrm{R}^{2}=3$-morpholinopropyl

3c, 7c $\quad \mathrm{R}^{1}=5-\mathrm{Br}, \quad \mathrm{R}^{2}=3$-morpholinopropyl

3d, 7d $\quad R^{1}=6-B r, \quad R^{2}=3$-morpholinopropyl

3e, 7e $\quad R^{1}=6-\mathrm{Cl}, \quad \mathrm{R}^{2}=3$-morpholinopropyl

3f, $7 f \quad R^{1}=6-F$

3g, 7g $\mathrm{R}^{1}=\mathrm{H}$,

3h, $7 \mathrm{~h} \quad \mathrm{R}^{1}=\mathrm{H}$

3i, $7 \mathbf{i} \quad R^{1}=H$, $\mathrm{R}^{2}=3$-morpholinopropyl $R^{2}=2$-morpholinoethyl $R^{2}=3$-morpholinopropyl $\mathrm{R}^{2}=4$-morpholinobutyl

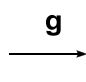

3j, $7 \mathrm{j} \quad \mathrm{R}^{1}=\mathrm{H}$

3k, 7k $\quad \mathrm{R}^{1}=\mathrm{H}$

3l, 7 I $\mathrm{R}^{1}=\mathrm{H}$,

$3 \mathrm{~m}, 7 \mathrm{~m} \quad \mathrm{R}^{1}=\mathrm{H}$

3n, 7n $\mathrm{R}^{1}=\mathrm{H}$,

3o, 7o $R^{1}=\mathrm{H}$,

3p, 7p $R^{1}=\mathrm{H}$

3q $\quad \mathrm{R}^{1}=\mathrm{H}$

$7 q \quad \mathrm{R}^{1}=\mathrm{H}$
$\mathrm{R}^{2}=3-(1 H$-imidazol-1-yl)propyl

$\mathrm{R}^{2}=4-(1 H$-imidazol-1-yl)butyl

$R^{2}=3-(1 H-1,2,4$-triazol-1-yl)propyl

$\mathrm{R}^{2}=3$-(piperidin-1-yl)propyl

$\mathrm{R}^{2}=3$-(pyrrolidin-1-yl)propyl

$R^{2}=$ methyl

$\mathrm{R}^{2}=$ butyl

$\mathrm{R}^{2}=\left(\mathrm{CH}_{2}\right)_{3} \mathrm{OTBDMS}$

$\mathrm{R}^{2}=$ hydroxypropyl

Reagents and conditions: (a) i $(\mathrm{COCl})_{2}, \mathrm{Et}_{2} \mathrm{O}$; ii $\mathrm{CH}_{3} \mathrm{ONa}, \mathrm{CH}_{3} \mathrm{OH}$; (b) (Boc) $)_{2} \mathrm{O}$, DMAP, THF; (c) $\mathrm{NaH}, \mathrm{DMF}, \mathrm{R}^{2} \mathrm{X}$; (d) $\mathrm{NaH}, \mathrm{Br}\left(\mathrm{CH}_{2}\right)_{4} \mathrm{Br}$, DMF; (e) $\mathrm{K}_{2} \mathrm{CO}_{3}$, morpholine, DMF; (f) i $\mathrm{HCl}$, $(\mathrm{COCl})_{2}, \mathrm{Et}_{2} \mathrm{O}$; ii $\mathrm{CH}_{3} \mathrm{ONa}, \mathrm{CH}_{3} \mathrm{OH}$; (g) i $t$-BuOK, THF; ii concentrated $\mathrm{HCl}$. 
Indole derivatives 1a-f were reacted with oxalyl chloride in $\mathrm{Et}_{2} \mathrm{O}$, followed by sodium methoxide to give compounds $\mathbf{2 a}-\mathbf{f}$. Reaction of $\mathbf{2 a}$ with $(\mathrm{Boc})_{2} \mathrm{O}$ in the presence of a catalytic amount of DMAP in THF afforded 3a. N-alkylation of $\mathbf{2 a}-\mathbf{f}$ with different alkyl halides resulted in key intermediates $\mathbf{3 b}-\mathbf{h}$ and $\mathbf{3 j}-\mathbf{q}$. In addition, treatment of indole with 1,4-dibromobutane afforded $\mathbf{4}$. N-substitution reaction of 4 with morpholine using $\mathrm{K}_{2} \mathrm{CO}_{3}$ as acid-trapping agent resulted in $\mathbf{5}$, which was then treated with oxalyl chloride, followed by sodium methoxide to give another key intermediate $3 \mathbf{i}$. Condensation of glyoxylic esters 3a-q with 2-(benzo[d]isoxazol-3-yl)acetamide 6 [22] in the presence of $t$-BuOK in THF afforded the target compounds $7 \mathbf{a}-\mathbf{q}$.

\subsection{Biological Activity and Molecular Modeling}

\subsubsection{Enzymatic Activity}

The GSK-3 $\beta$ inhibitory potency of all target compounds was examined. In addition, selected compounds $\mathbf{7 c}, \mathbf{7 j}$ and $7 \mathbf{0}$ were also tested for their inhibitory potency against other kinases (PKCepsilon, JAK2, BRAF, IKK2, Drak2) to assess kinase selectivity. Staurosporine, a well known kinase inhibitor was used as the reference compound [19]. The results are listed in Tables 1 and 2. As indicated in Table 1, most of the tested compounds showed similar or more potent GSK-3 $\beta$ inhibitory activity as compared to that of staurosporine. The potency of GSK-3 $\beta$ inhibition of tested compounds was mainly influenced by the substitutions on the indole ring and $\mathrm{N}^{1}$-position of the indole ring.

As expected, the introduction of suitable hydrophilic side chains at $\mathrm{N}^{1}$-position of the indole ring gave an obvious enhancement of GSK-3 $\beta$ inhibitory activity (i.e., $\mathbf{7 a}, \mathbf{7 h}, \mathbf{7} \mathbf{j}-\mathbf{l}, \mathbf{7 q}$ ). Among them, compound $7 \mathbf{j}$ with an imidazole group at the end of $\mathrm{N}^{1}$-propyl chain exhibited the most potent GSK-3 $\beta$ inhibitory activity, with an $\mathrm{IC}_{50}$ of $0.73 \mathrm{nM}$, which was about 460 -fold more potent than that of compound 7a $\left(\mathrm{IC}_{50}=332.2 \mathrm{nM}\right)$. Replacement of the terminal imidazole group in $7 \mathbf{j}$ with other substituents such as 1,2,4-triazole $\left(7 \mathbf{l}, \mathrm{IC}_{50}=20.9 \mathrm{nM}\right)$, hydroxyl $\left(\mathbf{7 q}, \mathrm{IC}_{50}=38.9 \mathrm{nM}\right)$, piperidine $\left(7 \mathbf{m}, \mathrm{IC}_{50}=511.8 \mathrm{nM}\right)$ and pyrrolidine $\left(7 \mathbf{o}, \mathrm{IC}_{50}=658.8 \mathrm{nM}\right)$ resulted in a 29 - to 915 -fold less inhibitory potency.

The results of inhibitory activities of compounds $\mathbf{7 g}-\mathbf{i}, \mathbf{7} \mathbf{j}$ and $\mathbf{7 k}$ showed that the length of the $\mathrm{N}^{1}$-alkyl linker affected GSK-3 $\beta$ inhibitory potency. For example, compound $7 \mathbf{j}\left(\mathrm{IC}_{50}=0.73 \mathrm{nM}\right)$ with a $\left(\mathrm{CH}_{2}\right)_{3}$ linker showed better inhibitory activity than compound $7 \mathbf{k}\left(\mathrm{IC}_{50}=89.8 \mathrm{nM}\right)$ with a $\left(\mathrm{CH}_{2}\right)_{4}$ linker. The same conclusion could also be drawn from comparison of the inhibitory potency of $7 \mathbf{h}$ and $7 \mathbf{i}$.

Interestingly, the introduction of a hydrophobic methyl group on the $\mathrm{N}^{1}$-position of the indole ring in $7 \mathbf{a}$ resulted in a 15-fold increase in inhibitory potency for GSK-3 $\beta$, while the replacement of the methyl with a large butyl group showed a 3-fold decrease in potency for GSK-3 $\beta$ inhibition.

When comparing the inhibitory activity of $\mathbf{7 b}-\mathbf{7} \mathbf{f}$ with $\mathbf{7 h}$, it suggested that different substituents on the indole ring affected the inhibitory potency for GSK-3 $\beta$. Compound $7 \mathbf{c}\left(\mathrm{IC}_{50}=10.2 \mathrm{nM}\right)$ with bromine at 5-position of the indole ring showed a 14-fold increase in inhibitory activity toward GSK-3 $\beta$ as compared to that of $7 \mathbf{h}\left(\mathrm{IC}_{50}=137.7 \mathrm{nM}\right)$. Fluorine at 6-position of the indole ring did not influence activity of $\mathbf{7 h}$, while bromine or chlorine at 6-position or methoxy at the 5-position showed less inhibitory potency. 
Table 1. GSK-3 $\beta$ inhibitory activity of the target compounds.<smiles>[R]n1cc(C2=C(c3noc4ccccc34)C(=O)NC2=O)c2c1C=C[R1]C=C2</smiles>

$7 a-q$

\begin{tabular}{|c|c|c|c|}
\hline Compounds & $\mathbf{R}^{1}$ & $\mathbf{R}^{2}$ & $\mathrm{IC}_{50}(\mathrm{nM}) \pm \mathrm{SE}^{\mathrm{a}}$ \\
\hline Staurosporine & & & $72.2 \pm 3.6$ \\
\hline $7 \mathbf{a}$ & $\mathrm{H}$ & $\mathrm{H}$ & $332.2 \pm 25.7$ \\
\hline $7 b$ & $5-\mathrm{OMe}$ & 3-morpholinopropyl & $357.2 \pm 17.1$ \\
\hline $7 \mathrm{c}$ & $5-\mathrm{Br}$ & 3-morpholinopropyl & $10.2 \pm 5.9$ \\
\hline 7d & $6-\mathrm{Br}$ & 3-morpholinopropyl & $209.6 \pm 8.9$ \\
\hline $7 e$ & $6-\mathrm{Cl}$ & 3-morpholinopropyl & $510.0 \pm 20.1$ \\
\hline $7 f$ & $6-\mathrm{F}$ & 3-morpholinopropyl & $126.7 \pm 3.2$ \\
\hline $7 \mathrm{~g}$ & $\mathrm{H}$ & 2-morpholinoethyl & $615.6 \pm 6.1$ \\
\hline $7 \mathrm{~h}$ & $\mathrm{H}$ & 3-morpholinopropyl & $137.7 \pm 6.0$ \\
\hline $7 \mathbf{i}$ & $\mathrm{H}$ & 4-morpholinobutyl & $410.7 \pm 8.2$ \\
\hline $7 \mathbf{j}$ & $\mathrm{H}$ & 3-(1H-imidazol-1-yl)propyl & $0.73 \pm 0.02$ \\
\hline $7 \mathbf{k}$ & $\mathrm{H}$ & 4-(1H-imidazol-1-yl)butyl & $89.8 \pm 4.5$ \\
\hline 71 & $\mathrm{H}$ & 3-(1H-1,2,4-triazol-1-yl)propyl & $20.9 \pm 5.1$ \\
\hline $7 \mathrm{~m}$ & $\mathrm{H}$ & 3-(piperidin-1-yl)propyl & $511.8 \pm 15.6$ \\
\hline $7 n$ & $\mathrm{H}$ & 3-(pyrrolidin-1-yl)propyl & $658.8 \pm 15.7$ \\
\hline 70 & $\mathrm{H}$ & methyl & $22.1 \pm 1.5$ \\
\hline $7 p$ & $\mathrm{H}$ & butyl & $58.7 \pm 2.8$ \\
\hline $7 q$ & $\mathrm{H}$ & hydroxypropyl & $38.9 \pm 2.6$ \\
\hline
\end{tabular}

${ }^{\text {a }} \mathrm{SE}$ : standard error mean.

Table 2. The selectivity to tested kinases of target compounds $7 \mathbf{c}, 7 \mathbf{j}$ and $7 \mathbf{0 .}$

\begin{tabular}{|c|c|c|c|c|}
\hline \multirow[t]{2}{*}{ Kinases } & \multicolumn{4}{|c|}{$\mathrm{IC}_{50}(\mathrm{nM}) \pm \mathrm{SE}^{\text {a }}$ or inhibition $\%$ at $0.8 \mu \mathrm{g} / \mathrm{mL}(\sim 2 \mu \mathrm{M})$} \\
\hline & Staurosporine & $7 \mathrm{c}$ & $7 \mathbf{j}$ & 70 \\
\hline GSK-3及 & $72.2 \pm 3.6$ & $10.2 \pm 5.9$ & $0.7 \pm 0.02$ & $22.1 \pm 1.5$ \\
\hline PKC-epsilon & $0.88 \pm 0.03$ & $12.1 \%$ & $10.9 \%$ & $21.2 \%$ \\
\hline JAK2 & $2.26 \pm 0.14$ & $0.1 \%$ & $4.9 \%$ & $9.4 \%$ \\
\hline BRAF & $14.37 \pm 0.86$ & $3.4 \%$ & $0.8 \%$ & $1.1 \%$ \\
\hline IKK2 & $1.21 \pm 0.13$ & $13.1 \%$ & $3.5 \%$ & $2.9 \%$ \\
\hline Drak2 & $25.82 \pm 2.11$ & $1.67 \%$ & $4.47 \%$ & $13.76 \%$ \\
\hline
\end{tabular}

${ }^{\mathrm{a}} \mathrm{SE}$ : standard error mean.

The data in Table 2 showed that staurosporine was a potent and nonselective kinase inhibitor as reported in the literature [14], which inhibits not only GSK-3 $\beta\left(\mathrm{IC}_{50}=72.2 \mathrm{nM}\right)$ but also many other kinases (e.g., PKC-epsilon, JAK2, BRAF, IKK2 and Drak2). Selected compounds 7c, 7j and 7o with high potency for GSK-3 $\beta$ inhibition were also evaluated for kinase selectivity against PKC-epsilon, JAK2, BRAF, IKK2 and Drak2. The results indicated that they displayed high selectivity for GSK-3 $\beta$ over other tested kinases. 


\subsubsection{Cellular Activity}

It has been implicated that GSK-3 $\beta$ is involved in multiple cellular processes, and its ability to hyperphosphorylate Tau protein and induce neurofibrillary tangle was intensively studied. Therefore, the cell-based assay examining Tau phosphorylation at Serine 396 represents a direct functional assay to measure the cellular activity of GSK-3 $\beta$ inhibitors [23]. Compounds $\mathbf{7 c}, \mathbf{7 f}, \mathbf{7 j}-\mathbf{l}$ and $\mathbf{7 0}-\mathbf{q}$ were tested for the ability to reduce Tau phosphorylation at Ser 396 in human neuroblastoma SH-SY5Y cells. LiCl, a well-known inhibitor of GSK-3 $\beta$ [24], was used as a positive control in this assay. As shown in Figure 2, all selected compound significantly reduced $\mathrm{A} \beta_{25-35}$-induced Tau hyper-phosphorylation, showing that these compounds can inhibit GSK-3 $\beta$ activity at the cellular level. The A $\beta$-induced Tau hyperphosphorylation results in neurofibrillary tangle formation, which plays an important role in Alzheimer's disease. Our data suggests that these novel GSK-3 $\beta$ inhibitors may have potential actions on inhibition of neurofibrillary tangle formation and would be tested for the treatment of Alzheimer's disease. In addition, the predictions about these compounds' brain permeability were performed using ADME module with Discovery Studio 2.1 software package. According to the prediction results (data not shown), most of them exhibited moderate blood-brain barrier permeability and would be further investigated for the treatment of Alzheimer's disease.

Figure 2. Effects of GSK-3 $\beta$ inhibitors on Tau phosphorylation (ser396) in SH-SY5Y cells.
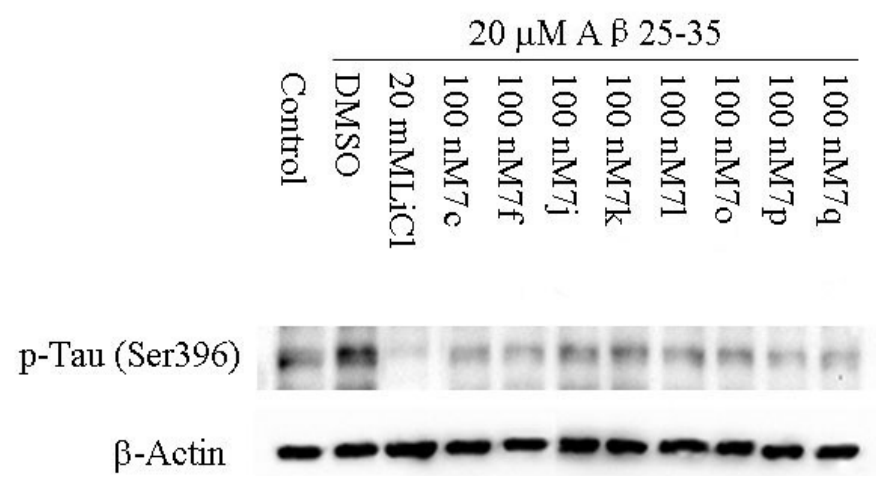

\subsubsection{Molecular Modeling}

To examine possible binding modes of compounds bearing different side chains at $\mathrm{N}^{1}$-position of the indole ring (e.g., 7j and 7n) with GSK-3 $\beta$, a docking analysis utilizing the C-DOCKER program within the Discovery Studio 2.1 software package was performed. The published X-ray crystal structure of GSK-3 $\beta$ (PDB ID: 1Q3D) [14] was used for the docking calculation. Figure 3 shows that both $\mathbf{7 j}$ and $\mathbf{7 n}$ could occupy the ATP binding site of GSK-3 $\beta$ with similar binding modes as a few other ATP-competitive inhibitors of GSK-3 $\beta$ [14,25], and they could thus serve as ATP-competitive inhibitors of GSK-3 $\beta$. The NH and carbonyl group in maleimide ring of $\mathbf{7 j}$ and $\mathbf{7 n}$ could form two key hydrogen bonds with Asp133 and Val135 of GSK-3 $\beta$. Besides, the 3-position nitrogen atom of the imidazole ring of $\mathbf{7} \mathbf{j}$ could form another hydrogen bond with Lys-183, which was not observed in $\mathbf{7 n}$. Furthermore, the CDOCKERENERAGE of $7 \mathbf{j}(-20.821 \mathrm{kcal} / \mathrm{mol})$ was much lower than that of $\mathbf{7 n}$ 
(2.971 kcal/mol). Thus, the molecular docking study results could explain the fact that $7 \mathbf{j}$ showed significantly improved potency compared to that of $\mathbf{7 n}$.

Figure 3. Docking of $\mathbf{7 j}$ to GSK-3 $\beta$ crystal structure. (A) Ribbon show of compound $\mathbf{7 j}$

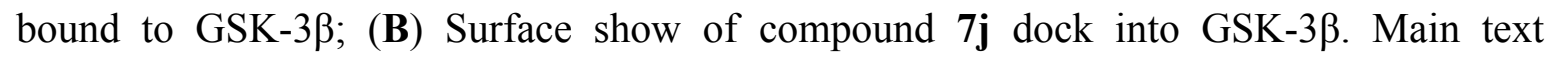
paragraph; (C) Ribbon show of compound 7n bound to GSK-3 $\beta$; (D) Surface show of compound $\mathbf{7 n}$ dock into GSK-3 $\beta$.
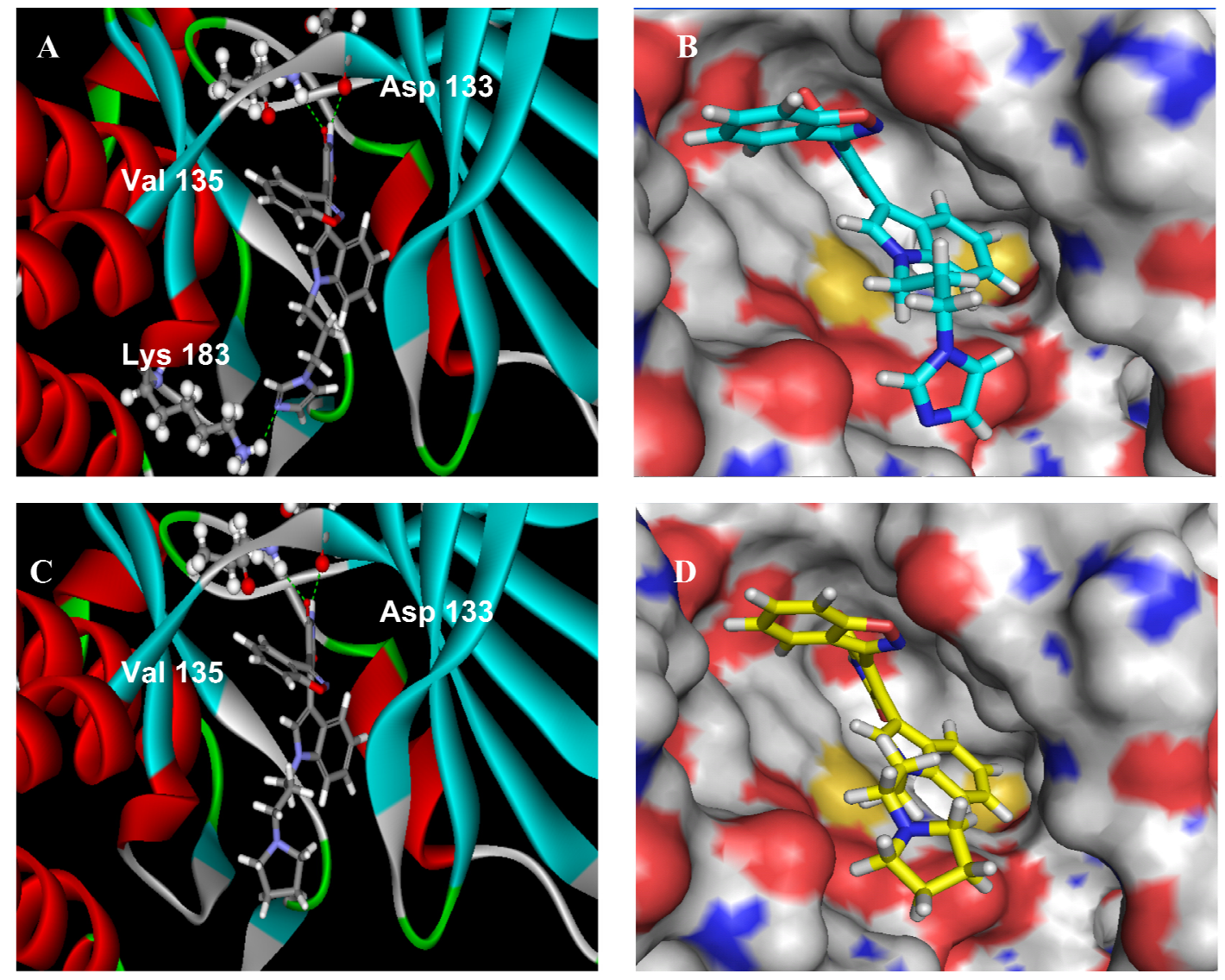

\section{Experimental}

\subsection{General}

Melting points were determined with a BÜCHI Melting Point B-450 apparatus (Büchi Labortechnik, Flawil, Switzerland). The ${ }^{1} \mathrm{H}-\mathrm{NMR}$ spectra were recorded in DMSO- $d_{6}$ or $\mathrm{CDCl}_{3}$ on Bruker Avance DMX 500 at $500 \mathrm{MHz}$ (chemical shifts are expressed as $\delta$ values relative to TMS as internal standard). ESI spectra (positive ion mode) were recorded on an Esquire-LC-00075 spectrometer. Elemental analyses were performed on an Eager 300 instrument. All reactions were monitored by thin-layer chromatography (TLC). All reagents were obtained from commercial sources and used without further purification unless stated. $\mathrm{Et}_{2} \mathrm{O}$ and $\mathrm{THF}$ were distilled from sodiumbenzophenone. DMF was distilled from calcium hydride. 


\subsection{General Procedure for the Preparation of $\mathbf{2 a}-\mathbf{f}$}

Oxalyl chloride $(3.40 \mathrm{~g}, 26 \mathrm{mmol})$ in $\mathrm{Et}_{2} \mathrm{O}(5 \mathrm{~mL})$ was added dropwise to a solution of indole adducts $1 \mathbf{a}-\mathbf{f}(26 \mathrm{mmol})$ in $\mathrm{Et}_{2} \mathrm{O}(30 \mathrm{~mL})$ at $0 \sim 5{ }^{\circ} \mathrm{C}[26,27]$. The reaction mixture was stirred under the same conditions for $1 \mathrm{~h}$, and a $20 \mathrm{wt} \%$ solution of $\mathrm{CH}_{3} \mathrm{ONa}$ in $\mathrm{MeOH}$ (14.05 g, $52 \mathrm{mmol}$ ) was added dropwise at $-30{ }^{\circ} \mathrm{C} \sim-20{ }^{\circ} \mathrm{C}$. After addition, the mixture was stirred for $30 \mathrm{~min}$ at room temperature, and poured into cold water $(100 \mathrm{~mL})$. The product was isolated with filtration, washed with dichloromethane and dried to afford $\mathbf{2 a}-\mathbf{f}$.

Methyl 2-(1H-indol-3-yl)-2-oxoacetate (2a). Light yellow solid, 86.3\% yield, mp: 208-210 ${ }^{\circ} \mathrm{C}$. ${ }^{1} \mathrm{H}-\mathrm{NMR}\left(\mathrm{DMSO}-d_{6}\right): \delta 12.48(\mathrm{brs}, 1 \mathrm{H}), 8.46(\mathrm{~d}, J=3.5 \mathrm{~Hz}, 1 \mathrm{H}), 8.16(\mathrm{~d}, J=7.0 \mathrm{~Hz}, 1 \mathrm{H}), 7.55(\mathrm{~d}$, $J=7.0 \mathrm{~Hz}, 1 \mathrm{H}), 7.32-7.26(\mathrm{~m}, 2 \mathrm{H}), 3.90(\mathrm{~s}, 3 \mathrm{H})$.

Methyl 2-(5-methoxy-1H-indol-3-yl)-2-oxoacetate (2b). Light yellow solid, 71.0\% yield, mp: $221-223{ }^{\circ} \mathrm{C}$. ${ }^{1} \mathrm{H}-\mathrm{NMR}$ (DMSO-d $)_{6}$ : $\delta 12.34$ (brs, $\left.1 \mathrm{H}\right), 8.37(\mathrm{~d}, J=3.0 \mathrm{~Hz}, 1 \mathrm{H}), 7.66(\mathrm{~d}, J=2.0 \mathrm{~Hz}, 1 \mathrm{H}), 7.45(\mathrm{~d}$, $J=9.0 \mathrm{~Hz}, 1 \mathrm{H}), 6.93(\mathrm{dd}, J=9.0,2.0 \mathrm{~Hz}, 1 \mathrm{H}), 3.89(\mathrm{~s}, 3 \mathrm{H}), 3.81(\mathrm{~s}, 3 \mathrm{H})$.

Methyl 2-(5-bromo-1H-indol-3-yl)-2-oxoacetate (2c). Light yellow solid, 55.3\% yield, mp: $215-217{ }^{\circ} \mathrm{C}$. ${ }^{1} \mathrm{H}-\mathrm{NMR}\left(\mathrm{DMSO}-d_{6}\right) \delta 12.59$ (brs, $\left.1 \mathrm{H}\right), 8.52(\mathrm{~d}, J=3.0 \mathrm{~Hz}, 1 \mathrm{H}), 8.30(\mathrm{~d}, J=2.0 \mathrm{~Hz}, 1 \mathrm{H}), 7.54(\mathrm{~d}$, $J=8.5 \mathrm{~Hz}, 1 \mathrm{H}), 7.45(\mathrm{dd}, J=8.5,2.0 \mathrm{~Hz}, 1 \mathrm{H}), 3.90(\mathrm{~s}, 3 \mathrm{H})$.

Methyl 2-(6-bromo-1H-indol-3-yl)-2-oxoacetate (2d). Light yellow solid, 58.9\% yield, mp: 207-209 ${ }^{\circ} \mathrm{C}$. ${ }^{1} \mathrm{H}-\mathrm{NMR}\left(\mathrm{DMSO}-d_{6}\right): \delta 12.50(\mathrm{brs}, 1 \mathrm{H}), 8.50(\mathrm{~s}, 1 \mathrm{H}), 8.10(\mathrm{~d}, J=8.5 \mathrm{~Hz}, 1 \mathrm{H}), 7.75(\mathrm{~d}, J=2.0 \mathrm{~Hz}$, $1 \mathrm{H}), 7.43(\mathrm{dd}, J=8.5,2.0 \mathrm{~Hz}, 1 \mathrm{H}), 3.90(\mathrm{~s}, 3 \mathrm{H})$.

Methyl 2-(6-chloro-1H-indol-3-yl)-2-oxoacetate (2e). Light yellow solid, 62.8\% yield, mp: $246-248{ }^{\circ} \mathrm{C}$. ${ }^{1} \mathrm{H}-\mathrm{NMR}\left(\mathrm{DMSO}-d_{6}\right): \delta 12.52$ (brs, $\left.1 \mathrm{H}\right), 8.51(\mathrm{~d}, J=3.5 \mathrm{~Hz}, 1 \mathrm{H}), 8.15(\mathrm{~d}, J=8.5 \mathrm{~Hz}, 1 \mathrm{H}), 7.62(\mathrm{~d}$, $J=2.0 \mathrm{~Hz}, 1 \mathrm{H}), 7.31(\mathrm{dd}, J=8.5,2.0 \mathrm{~Hz}, 1 \mathrm{H}), 3.90(\mathrm{~s}, 3 \mathrm{H})$.

Methyl 2-(6-fluoro-1H-indol-3-yl)-2-oxoacetate (2f). Light yellow solid, 60.3\% yield, mp: $182-184{ }^{\circ} \mathrm{C}$. ${ }^{1} \mathrm{H}-\mathrm{NMR}\left(\mathrm{DMSO}-d_{6}\right): \delta 12.48(\mathrm{brs}, 1 \mathrm{H}), 8.48(\mathrm{~s}, 1 \mathrm{H}), 8.15(\mathrm{dd}, J=8.5,5.5 \mathrm{~Hz}, 1 \mathrm{H}), 7.36(\mathrm{dd}, J=9.5$, $2.0 \mathrm{~Hz}, 1 \mathrm{H}), 7.15(\mathrm{td}, J=9.5,2.0 \mathrm{~Hz}, 1 \mathrm{H}), 3.90(\mathrm{~s}, 3 \mathrm{H})$.

\section{3. tert-Butyl 3-(2-methoxy-2-oxoacetyl)-1H-indole-1-carboxylate (3a)}

A solution of $2 \mathrm{a}(2.0 \mathrm{~g}, 9.8 \mathrm{mmol})$, Boc anhydride $(2.7 \mathrm{~g}, 12.3 \mathrm{mmol})$ and DMAP (0.01 g) in dry THF $(100 \mathrm{~mL})$ was reacted for $3 \mathrm{~h}$ at room temperature. The solvent was removed under vacuum, and the residue was recrystallized from petroleum ether/ethyl acetate to give $2.0 \mathrm{~g} \mathrm{(67.1 \% )} \mathrm{3a} \mathrm{as} \mathrm{a} \mathrm{white}$

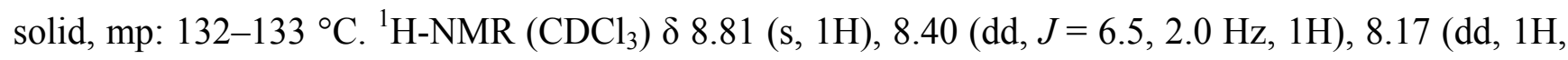
$J=6.5,1.5 \mathrm{~Hz}, 1 \mathrm{H}), 7.41-7.38(\mathrm{~m}, 2 \mathrm{H}), 3.98(\mathrm{~s}, 3 \mathrm{H}), 1.71(\mathrm{~s}, 9 \mathrm{H})$.

\subsection{General Procedure for the Preparation of $\mathbf{3 b}-\mathbf{h}, \mathbf{3} \mathbf{j}-\mathbf{n}$ and $\mathbf{3 q}$}

$70 \% \mathrm{NaH}(0.51 \mathrm{~g}, 14.8 \mathrm{mmol})$ was added portionwise to a solution of $\mathbf{2 a}-\mathbf{f}(14.8 \mathrm{mmol})$ in DMF $(30 \mathrm{~mL})$ at $0 \sim 5{ }^{\circ} \mathrm{C}$. The reaction mixture was warmed to room temperature and stirred for $30 \mathrm{~min}$. 
After that, the appropriate $\mathrm{R}^{2} \mathrm{X}$ [4-(3-chloropropyl)morpholine, 4-(2-chloroethyl)morpholine, 1-(3chloropropyl)-1H-imidazole, 1-(4-chlorobutyl)-1H-imidazole, 1-(3-chloropropyl)-1H-1,2,4-triazole, 1-(3-chloropropyl)piperidine, 1-(3-chloropropyl)pyrrolidine or (3-bromopropoxy)(tert-butyl)dimethylsilane)] $(19.2 \mathrm{mmol})$ was added. Then the mixture was headed to $55 \sim 60{ }^{\circ} \mathrm{C}$ and reacted for $12 \mathrm{~h}$. After cooling, the mixture was poured into cold water $(300 \mathrm{~mL})$ and extracted with ethyl acetate $(3 \times 100 \mathrm{~mL})$. The organic phase was combined, washed with brine $(3 \times 300 \mathrm{~mL})$, dried over $\mathrm{Na}_{2} \mathrm{SO}_{4}$ and concentrated in vacuo. The residue was purified by flash column chromatography on silica gel using ethyl acetate/methanol (50:1, v/v) as eluent to afford $\mathbf{3 b}-\mathbf{h}, \mathbf{3} \mathbf{j}-\mathbf{n}$ and $\mathbf{3 q}$.

Methyl 2-(5-methoxy-1-(3-morpholinopropyl)-1H-indol-3-yl)-2-oxoacetate (3b). Light yellow solid, 64.7\% yield, mp: $67-68{ }^{\circ} \mathrm{C} .{ }^{1} \mathrm{H}-\mathrm{NMR}\left(\mathrm{CDCl}_{3}\right): \delta 8.38(\mathrm{~s}, 1 \mathrm{H}), 7.95(\mathrm{~d}, J=2.5 \mathrm{~Hz}, 1 \mathrm{H}), 7.32(\mathrm{~d}, J=9.0 \mathrm{~Hz}$, $1 \mathrm{H}), 6.97(\mathrm{dd}, J=9.0,2.5 \mathrm{~Hz}, 1 \mathrm{H}), 4.28$ (t, $J=7.0 \mathrm{~Hz}, 2 \mathrm{H}), 3.95$ (s, 3H), 3.91 (s, 3H), 3.77-3.70 (m, 4H), 2.42-2.38 (m, 4H), $2.27(\mathrm{t}, J=6.5 \mathrm{~Hz}, 2 \mathrm{H}), 2.06-2.01(\mathrm{~m}, 2 \mathrm{H})$. ESI-MS: $m / z[\mathrm{M}+\mathrm{H}]^{+} 361$. Anal. Calcd for $\mathrm{C}_{19} \mathrm{H}_{24} \mathrm{~N}_{2} \mathrm{O}_{5}$ : C, 63.32; H, 6.71; N, 7.77. Found: C, 63.49; H, 6.68; N, 7.49.

Methyl 2-(5-bromo-1-(3-morpholinopropyl)-1H-indol-3-yl)-2-oxoacetate (3c). Light yellow solid, 56.6\% yield, mp: $112-113{ }^{\circ} \mathrm{C} .{ }^{1} \mathrm{H}-\mathrm{NMR}\left(\mathrm{CDCl}_{3}\right) \delta 8.43(\mathrm{~s}, 1 \mathrm{H}), 8.31(\mathrm{~d}, J=8.5 \mathrm{~Hz}, 1 \mathrm{H}), 7.67(\mathrm{~d}$, $J=2.0 \mathrm{~Hz}, 1 \mathrm{H}), 7.45$ (dd, $J=8.5,2.0 \mathrm{~Hz}, 1 \mathrm{H}), 4.29$ (t, $J=7.0 \mathrm{~Hz}, 2 \mathrm{H}), 3.95$ (s, 3H), 3.81-3.75 (m, 4H), 2.43-2.39 (m, 4H), $2.25(\mathrm{t}, J=6.5 \mathrm{~Hz}, 2 \mathrm{H}), 2.05-2.01(\mathrm{~m}, 2 \mathrm{H})$. ESI-MS: $m / z[\mathrm{M}+\mathrm{H}]^{+} 409$. Anal. Calcd for $\mathrm{C}_{18} \mathrm{H}_{21} \mathrm{BrN}_{2} \mathrm{O}_{4}: \mathrm{C}, 52.82 ; \mathrm{H}, 5.17 ; \mathrm{N}, 6.84$. Found: C, 52.96; H, 5.23; N, 6.76.

Methyl 2-(6-bromo-1-(3-morpholinopropyl)-1H-indol-3-yl)-2-oxoacetate (3d). Light yellow solid, 54.9\% yield, mp: $102-103{ }^{\circ} \mathrm{C} .{ }^{1} \mathrm{H}-\mathrm{NMR}\left(\mathrm{CDCl}_{3}\right): \delta 8.43(\mathrm{~s}, 1 \mathrm{H}), 8.31(\mathrm{~d}, J=8.5 \mathrm{~Hz}, 1 \mathrm{H}), 7.67(\mathrm{~d}$, $J=1.5 \mathrm{~Hz}, 1 \mathrm{H}), 7.45(\mathrm{dd}, J=8.5,1.5 \mathrm{~Hz}, 1 \mathrm{H}), 4.29$ (t, $J=6.5 \mathrm{~Hz}, 2 \mathrm{H}), 3.95(\mathrm{~s}, 3 \mathrm{H}), 3.86-3.69$ (m, 4H), 2.43-2.39 (m, 4H), $2.25(\mathrm{t}, J=6.5 \mathrm{~Hz}, 2 \mathrm{H}), 2.05-2.01(\mathrm{~m}, 2 \mathrm{H})$. ESI-MS: $m / z[\mathrm{M}+\mathrm{H}]^{+} 409$. Anal. Calcd for $\mathrm{C}_{18} \mathrm{H}_{21} \mathrm{BrN}_{2} \mathrm{O}_{4}$ : C, 52.82; H, 5.17; N, 6.84. Found: C, 52.68; H, 5.26; N, 6.68.

Methyl 2-(6-chloro-1-(3-morpholinopropyl)-1H-indol-3-yl)-2-oxoacetate (3e). Light yellow solid, 59.1\% yield, mp: $115-116{ }^{\circ} \mathrm{C} .{ }^{1} \mathrm{H}-\mathrm{NMR}\left(\mathrm{CDCl}_{3}\right): \delta 8.42(\mathrm{~s}, 1 \mathrm{H}), 8.34(\mathrm{~d}, J=8.5 \mathrm{~Hz}, 1 \mathrm{H}), 7.49(\mathrm{~d}$, $J=1.5 \mathrm{~Hz}, 1 \mathrm{H}), 7.30(\mathrm{dd}, J=8.5,1.5 \mathrm{~Hz}, 1 \mathrm{H}), 4.28(\mathrm{t}, J=6.5 \mathrm{~Hz}, 2 \mathrm{H}), 3.94(\mathrm{~s}, 3 \mathrm{H}), 3.80-3.70$ (m, 4H), 2.43-2.37 (m, 4H), $2.24(\mathrm{t}, J=6.5 \mathrm{~Hz}, 2 \mathrm{H}), 2.04-2.00(\mathrm{~m}, 2 \mathrm{H})$. ESI-MS: $m / z[\mathrm{M}+\mathrm{H}]^{+} 365$. Anal. Calcd for $\mathrm{C}_{18} \mathrm{H}_{21} \mathrm{ClN}_{2} \mathrm{O}_{4}$ : C, 59.26; H, 5.80; N, 7.68. Found: C, 59.44; H, 5.78; N, 7.45.

Methyl 2-(6-fluoro-1-(3-morpholinopropyl)-1H-indol-3-yl)-2-oxoacetate (3f). Light yellow solid, 64.8\% yield, mp:116-117 ${ }^{\circ} \mathrm{C} .{ }^{1} \mathrm{H}-\mathrm{NMR}\left(\mathrm{CDCl}_{3}\right): \delta 8.44(\mathrm{~s}, 1 \mathrm{H}), 8.38(\mathrm{dd}, J=8.5,5.5 \mathrm{~Hz}, 1 \mathrm{H}), 7.16$ $(\mathrm{dd}, J=9.0,2.0 \mathrm{~Hz}, 1 \mathrm{H}), 7.13-7.06(\mathrm{~m}, 1 \mathrm{H}), 4.27(\mathrm{t}, J=6.5 \mathrm{~Hz}, 2 \mathrm{H}), 3.95(\mathrm{~s}, 3 \mathrm{H}), 3.79-3.70(\mathrm{~m}, 4 \mathrm{H})$, 2.43-2.39 (m, 4H), $2.27(\mathrm{t}, J=6.5 \mathrm{~Hz}, 2 \mathrm{H}), 2.06-2.00(\mathrm{~m}, 2 \mathrm{H})$. ESI-MS: $m / z[\mathrm{M}+\mathrm{H}]^{+} 349$. Anal. Calcd for $\mathrm{C}_{18} \mathrm{H}_{21} \mathrm{FN}_{2} \mathrm{O}_{4}$ : C, 62.06; H, 6.08; N, 8.04. Found: $\mathrm{C}, 62.18 ; \mathrm{H}, 6.23 ; \mathrm{N}, 8.25$.

Methyl 2-(1-(2-morpholinoethyl)-1H-indol-3-yl)-2-oxoacetate (3g). Light yellow solid, 52.4\% yield, mp: $110-112{ }^{\circ} \mathrm{C} .{ }^{1} \mathrm{H}-\mathrm{NMR}\left(\mathrm{CDCl}_{3}\right): \delta 8.51(\mathrm{~s}, 1 \mathrm{H}), 8.49-8.44(\mathrm{~m}, 1 \mathrm{H}), 7.43-7.39(\mathrm{~m}, 1 \mathrm{H}), 7.38-7.35$ $(\mathrm{m}, 2 \mathrm{H}), 4.29(\mathrm{t}, J=6.5 \mathrm{~Hz}, 2 \mathrm{H}), 3.97(\mathrm{~s}, 3 \mathrm{H}), 3.75-3.69(\mathrm{~m}, 4 \mathrm{H}), 2.81(\mathrm{t}, J=6.5 \mathrm{~Hz}, 2 \mathrm{H}), 2.54-2.47$ 
(m, 4H). ESI-MS: $m / z[\mathrm{M}+\mathrm{H}]^{+}$317. Anal. Calcd for $\mathrm{C}_{17} \mathrm{H}_{20} \mathrm{~N}_{2} \mathrm{O}_{4}: \mathrm{C}, 64.54 ; \mathrm{H}, 6.37 ; \mathrm{N}, 8.86$. Found: C, $64.71 ; \mathrm{H}, 6.68 ; \mathrm{N}, 8.68$.

Methyl 2-(1-(3-morpholinopropyl)-1H-indol-3-yl)-2-oxoacetate (3h). Light yellow solid, 67.5\% yield, mp: $103-104{ }^{\circ} \mathrm{C} .{ }^{1} \mathrm{H}-\mathrm{NMR}\left(\mathrm{CDCl}_{3}\right): \delta 8.47-8.43(\mathrm{~m}, 2 \mathrm{H}), 7.46-7.41(\mathrm{~m}, 1 \mathrm{H}), 7.38-7.32(\mathrm{~m}, 2 \mathrm{H}), 4.32$ (t, $J=6.5 \mathrm{~Hz}, 2 \mathrm{H}), 3.95(\mathrm{~s}, 3 \mathrm{H}), 3.78-3.72(\mathrm{~m}, 4 \mathrm{H}), 2.44-2.38(\mathrm{~m}, 4 \mathrm{H}), 2.28(\mathrm{t}, J=6.5 \mathrm{~Hz}, 2 \mathrm{H})$, 2.08-2.02 (m, 2H). ESI-MS: $m / z[\mathrm{M}+\mathrm{H}]^{+}$331. Anal. Calcd for $\mathrm{C}_{18} \mathrm{H}_{22} \mathrm{~N}_{2} \mathrm{O}_{4}$ : C, 65.44; H, 6.71; N, 8.48. Found: C, 65.27; H, 6.68; N, 8.58.

Methyl 2-(1-(3-(1H-imidazol-1-yl)propyl)-1H-indol-3-yl)-2-oxoacetate (3j). Light yellow solid, 52.8\% yield, mp: $72-73{ }^{\circ} \mathrm{C} .{ }^{1} \mathrm{H}-\mathrm{NMR}\left(\mathrm{CDCl}_{3}\right) \delta 8.51-8.46(\mathrm{~m}, 1 \mathrm{H}), 8.36(\mathrm{~s}, 1 \mathrm{H}), 7.53(\mathrm{~s}, 1 \mathrm{H}), 7.42-7.34(\mathrm{~m}$, 2H), 7.30-7.27 (m, 1H), $7.17(\mathrm{~s}, 1 \mathrm{H}), 6.96(\mathrm{~s}, 1 \mathrm{H}), 4.20(\mathrm{t}, J=7.0 \mathrm{~Hz}, 2 \mathrm{H}), 4.00$ (t, J=7.0 Hz, 2H), $3.98(\mathrm{~s}, 3 \mathrm{H}), 2.48-2.40(\mathrm{~m}, 2 \mathrm{H})$. ESI-MS: $m / z[\mathrm{M}+\mathrm{H}]^{+}$312. Anal. Calcd for $\mathrm{C}_{17} \mathrm{H}_{17} \mathrm{~N}_{3} \mathrm{O}_{3}$ : C, 65.58; $\mathrm{H}$, 5.50; N, 13.50. Found: C, 65.59; H, 4.88; N, 13.68 .

Methyl 2-(1-(4-(1H-imidazol-1-yl)butyl)-1H-indol-3-yl)-2-oxoacetate (3k). Light yellow solid, 41.6\% yield, ${ }^{1} \mathrm{H}-\mathrm{NMR}\left(\mathrm{CDCl}_{3}\right) \delta 8.50-8.42(\mathrm{~m}, 1 \mathrm{H}), 8.35(\mathrm{~s}, 1 \mathrm{H}), 7.44(\mathrm{~s}, 1 \mathrm{H}), 7.38-7.32(\mathrm{~m}, 3 \mathrm{H}), 7.06(\mathrm{~s}$, $1 \mathrm{H}), 6.85(\mathrm{~s}, 1 \mathrm{H}), 4.19(\mathrm{t}, J=7.0 \mathrm{~Hz}, 2 \mathrm{H}), 3.96(\mathrm{~s}, 3 \mathrm{H}), 3.93$ (t, $J=7.0 \mathrm{~Hz}, 2 \mathrm{H}), 1.95-1.86$ $(\mathrm{m}, 2 \mathrm{H}), 1.87-1.77(\mathrm{~m}, 2 \mathrm{H})$. ESI-MS: $m / z[\mathrm{M}+\mathrm{H}]^{+}$326. Anal. Calcd for $\mathrm{C}_{18} \mathrm{H}_{19} \mathrm{~N}_{3} \mathrm{O}_{3}$ : C, 66.45; $\mathrm{H}$, 5.89; N, 12.91. Found: C, 66.62; H, 5.77; N, 12.85 .

Methyl 2-(1-(3-(1H-1,2,4-triazol-1-yl)propyl)-1H-indol-3-yl)-2-oxoacetate (31). Light yellow solid, 64.5\% yield, mp: $98-99{ }^{\circ} \mathrm{C} .{ }^{1} \mathrm{H}-\mathrm{NMR}\left(\mathrm{CDCl}_{3}\right) \delta 8.49-8.45(\mathrm{~m}, 1 \mathrm{H}), 8.44(\mathrm{~s}, 1 \mathrm{H}), 8.08(\mathrm{~s}, 1 \mathrm{H}), 8.05(\mathrm{~s}$, 1H), 7.40-7.36 (m, 2H), 7.35-7.32 (m, 1H), 4.31 (t, J=7.0 Hz, 2H), 4.18 (t, J=7.0 Hz, 2H), 3.97 (s, 3H), 2.59-2.49 (m, 2H). ESI-MS: $m / z[\mathrm{M}+\mathrm{H}]^{+}$313. Anal. Calcd for $\mathrm{C}_{16} \mathrm{H}_{16} \mathrm{~N}_{4} \mathrm{O}_{3}: \mathrm{C}, 61.53 ; \mathrm{H}, 5.16 ; \mathrm{N}$, 17.94. Found: C, 61.69; H, 5.31; N, 17.99.

Methyl 2-oxo-2-(1-(3-(piperidin-1-yl)propyl)-1H-indol-3-yl)acetate (3m). Light yellow solid, 52.4\% yield, mp: 66-67 ${ }^{\circ} \mathrm{C} .{ }^{1} \mathrm{H}-\mathrm{NMR}$ (DMSO- $\left.d_{6}\right) \delta 8.47(\mathrm{~s}, 1 \mathrm{H}), 8.20(\mathrm{~d}, J=7.5 \mathrm{~Hz}, 1 \mathrm{H}), 7.68(\mathrm{~d}, J=7.5 \mathrm{~Hz}$, 1H), 7.39-7.27 (m, 2H), $4.34(\mathrm{t}, J=7.0 \mathrm{~Hz}, 2 \mathrm{H}), 3.90(\mathrm{~s}, 3 \mathrm{H}), 2.29-2.18(\mathrm{~m}, 4 \mathrm{H}), 2.13(\mathrm{t}, J=6.5 \mathrm{~Hz}$, 2H), $1.96-1.90(\mathrm{~m}, 2 \mathrm{H}), 1.55-1.41(\mathrm{~m}, 4 \mathrm{H}), 1.40-1.30(\mathrm{~m}, 2 \mathrm{H})$. ESI-MS: $m / z[\mathrm{M}+\mathrm{H}]^{+} 329$. Anal. Calcd for $\mathrm{C}_{19} \mathrm{H}_{24} \mathrm{~N}_{2} \mathrm{O}_{3}$ : C, 69.49; H, 7.37; N, 8.53. Found: C, 69.69; H, 7.68; N, 8.48.

Methyl 2-oxo-2-(1-(3-(pyrrolidin-1-yl)propyl)-1H-indol-3-yl)acetate (3n). Light yellow solid, 48.5\% yield, mp: $56-58{ }^{\circ} \mathrm{C} .{ }^{1} \mathrm{H}-\mathrm{NMR}\left(\mathrm{DMSO}-d_{6}\right) \delta 8.50(\mathrm{~s}, 1 \mathrm{H}), 8.19(\mathrm{~d}, J=8.0 \mathrm{~Hz}, 1 \mathrm{H}), 7.69(\mathrm{~d}, J=8.0 \mathrm{~Hz}$, 1H), 7.39-7.27 (m, 2H), $4.37(\mathrm{t}, J=7.0 \mathrm{~Hz}, 2 \mathrm{H}), 3.90(\mathrm{~s}, 3 \mathrm{H}), 2.42-2.39(\mathrm{~m}, 4 \mathrm{H}), 2.35$ (t, $J=6.5 \mathrm{~Hz}$, $2 \mathrm{H}), 2.00-1.92(\mathrm{~m}, 2 \mathrm{H}), 1.72-1.67(\mathrm{~m}, 4 \mathrm{H})$. ESI-MS: $m / z[\mathrm{M}+\mathrm{H}]^{+} 311$. Anal. Calcd for $\mathrm{C}_{18} \mathrm{H}_{18} \mathrm{~N}_{2} \mathrm{O}_{3}$ : C, 69.66; H, 5.85; N, 9.03. Found: C, 69.78; H,5.96; N, 9.22.

Methyl 2-(1-(3-((tert-butyldimethylsilyl)oxy)propyl)-1H-indol-3-yl)-2-oxoacetate (3q). Light yellow solid, 62.5\% yield, mp: $69-71{ }^{\circ} \mathrm{C} .{ }^{1} \mathrm{H}-\mathrm{NMR}\left(\mathrm{CDCl}_{3}\right): \delta 8.40-8.36(\mathrm{~m}, 1 \mathrm{H}), 8.31(\mathrm{~s}, 1 \mathrm{H}), 7.39-7.34(\mathrm{~m}$, 1H), 7.31-7.24 (m, 2H), $4.27(\mathrm{t}, J=7.0 \mathrm{~Hz}, 2 \mathrm{H}), 3.88(\mathrm{~s}, 3 \mathrm{H}), 3.52(\mathrm{t}, J=7.0 \mathrm{~Hz}, 2 \mathrm{H}), 2.06-1.92$ (m, $2 \mathrm{H}), 0.87(\mathrm{~s}, 9 \mathrm{H}), 0.01(\mathrm{~s}, 6 \mathrm{H})$. ESI-MS: $m / z[\mathrm{M}+\mathrm{H}]^{+}$349. Anal. Calcd for $\mathrm{C}_{20} \mathrm{H}_{29} \mathrm{NO}_{4} \mathrm{Si}: \mathrm{C}, 63.97 ; \mathrm{H}$, 7.78; N, 3.73. Found: C, 64.05; H, 7.86; N, 3.65. 


\subsection{1-(4-Bromobutyl)-1H-indole (4)}

$70 \% \mathrm{NaH}(1.77 \mathrm{~g}, 51.6 \mathrm{mmol})$ was added portionwise to a solution of indole $(5.0 \mathrm{~g}, 43.0 \mathrm{mmol})$ in DMF $(50 \mathrm{~mL})$ at $0 \sim 5{ }^{\circ} \mathrm{C}$. The mixture was warmed to room temperature and stirred for $30 \mathrm{~min}$. After that, it was added dropwise to a mixture of 1,4-dibromobutane (46.4 g, $215 \mathrm{mmol})$ in DMF (10 mL) at room temperature, and stirred for $12 \mathrm{~h}$. The mixture was then poured into cold water $(300 \mathrm{~mL})$ and extracted with ethyl acetate $(3 \times 100 \mathrm{~mL})$. The organic phase was combined, washed with brine $(3 \times 300 \mathrm{~mL})$, dried over $\mathrm{Na}_{2} \mathrm{SO}_{4}$ and concentrated in vacuo. The residue was purified by flash column chromatography on silica gel using petroleum ether/ethyl acetate $(80: 1, \mathrm{v} / \mathrm{v})$ as eluent to afford $7.6 \mathrm{~g}$ $(71.2 \%)$ of 4 as a colorless liquid. ${ }^{1} \mathrm{H}-\mathrm{NMR}\left(\mathrm{CDCl}_{3}\right): \delta 7.66(\mathrm{~d}, J=8.0 \mathrm{~Hz}, 1 \mathrm{H}), 7.36(\mathrm{~d}, J=8.0 \mathrm{~Hz}$, $1 \mathrm{H}), 7.25-7.22(\mathrm{~m}, 1 \mathrm{H}), 7.14-7.11(\mathrm{~m}, 2 \mathrm{H}), 6.53(\mathrm{~d}, J=3.0 \mathrm{~Hz}, 1 \mathrm{H}), 4.19(\mathrm{t}, J=7.0 \mathrm{~Hz}, 2 \mathrm{H}), 3.40$ $(\mathrm{t}, J=6.5 \mathrm{~Hz}, 2 \mathrm{H}), 2.07-2.00(\mathrm{~m}, 2 \mathrm{H}), 1.90-1.85(\mathrm{~m}, 2 \mathrm{H})$.

\subsection{4-(4-(1H-Indol-1-yl)butyl)morpholine (5)}

A mixture of $4(2.0 \mathrm{~g}, 7.9 \mathrm{mmol})$, morpholine $(6.9 \mathrm{~g}, 79.0 \mathrm{mmol})$ and potassium carbonate $(1.9 \mathrm{~g}$, $13.8 \mathrm{mmol})$ in DMF $(30 \mathrm{~mL})$ was stirred at $50{ }^{\circ} \mathrm{C}$ for $6 \mathrm{~h}[28-40]$. After cooling, the mixture was poured into cold water $(200 \mathrm{~mL})$ and extracted with ethyl acetate $(3 \times 100 \mathrm{~mL})$. The organic phase was combined, washed with brine $(3 \times 300 \mathrm{~mL})$, dried over $\mathrm{Na}_{2} \mathrm{SO}_{4}$ and concentrated in vacuum. The residue was purified by flash column chromatography on silica gel using petroleum ether/ethyl acetate/triethylamine $(20: 100: 1, \mathrm{v} / \mathrm{v} / \mathrm{v})$ as eluent to afford $1.63 \mathrm{~g}(80.1 \%)$ of 5 as a colorless liquid, ${ }^{1} \mathrm{H}-\mathrm{NMR}\left(\mathrm{CDCl}_{3}\right): \delta 7.65(\mathrm{~d}, J=8.0 \mathrm{~Hz}, 1 \mathrm{H}), 7.37(\mathrm{~d}, J=8.0 \mathrm{~Hz}, 1 \mathrm{H}), 7.24-7.21(\mathrm{~m}, 1 \mathrm{H}), 7.14-7.11$ $(\mathrm{m}, 2 \mathrm{H}), 6.51(\mathrm{~d}, J=3.0 \mathrm{~Hz}, 1 \mathrm{H}), 4.17$ (t, $J=7.0 \mathrm{~Hz}, 2 \mathrm{H}), 3.75-3.70(\mathrm{~m}, 4 \mathrm{H}), 2.39-2.33(\mathrm{~m}, 6 \mathrm{H})$, 1.93-1.87 (m, 2H), 1.57-1.50 (m, 2H). ESI-MS: $m / z[\mathrm{M}+\mathrm{H}]^{+}$259. Anal. Calcd for $\mathrm{C}_{16} \mathrm{H}_{22} \mathrm{~N}_{2} \mathrm{O}: \mathrm{C}$, 74.38; H, 8.58; N, 10.84. Found: C, 74.53; H, 8.64; N, 10.93.

\subsection{Methyl 2-(1-(4-morpholinobutyl)-1H-indol-3-yl)-2-oxoacetate (3i)}

$1 \mathrm{M} \mathrm{HCl}$ in dioxane $(5.5 \mathrm{~mL}, 5.5 \mathrm{mmol})$ was added to a solution of $5(1.29 \mathrm{~g}, 5.0 \mathrm{mmol})$ in $\mathrm{CH}_{3} \mathrm{CN}$ $(30 \mathrm{~mL})$ and $\mathrm{Et}_{2} \mathrm{O}(30 \mathrm{~mL})$ at room temperature and stirred for $30 \mathrm{~min}$. After that, oxalyl chloride $(0.76 \mathrm{~g}$, $6.0 \mathrm{mmol})$ in $\mathrm{Et}_{2} \mathrm{O}(5 \mathrm{~mL})$ was added dropwise at $0 \sim 5{ }^{\circ} \mathrm{C}$ and the reaction mixture was stirred for $2 \mathrm{~h}$ at the same temperature. $\mathrm{MeOH}(10 \mathrm{~mL})$ was added dropwise to the mixture at $0 \sim 5{ }^{\circ} \mathrm{C}$ and the result solution was stirred for $2 \mathrm{~h}$ at room temperature, then poured into a cold aqueous $\mathrm{NaHCO}_{3}$ solution and extracted with ethyl acetate $(3 \times 50 \mathrm{~mL})$. The organic phase was combined, washed with brine $(150 \mathrm{~mL})$, dried over $\mathrm{Na}_{2} \mathrm{SO}_{4}$ and concentrated under vacuum. The residue was purified by flash column chromatography on silica gel using ethyl acetate/methanol $(50: 1, \mathrm{v} / \mathrm{v})$ as eluent to afford $0.94 \mathrm{~g}$ (54.6\%) of $3 \mathbf{i}$ as a light yellow solid, mp: $84-85{ }^{\circ} \mathrm{C} .{ }^{1} \mathrm{H}-\mathrm{NMR}\left(\mathrm{CDCl}_{3}\right): \delta 8.48-8.44(\mathrm{~m}, 1 \mathrm{H}), 8.40$ (s, $1 \mathrm{H}), 7.44-7.38(\mathrm{~m}, 1 \mathrm{H}), 7.36-7.34(\mathrm{~m}, 2 \mathrm{H}), 4.23(\mathrm{t}, J=7.5 \mathrm{~Hz}, 2 \mathrm{H}), 3.97(\mathrm{~s}, 3 \mathrm{H}), 3.73-3.65(\mathrm{~m}, 4 \mathrm{H})$, 2.39-2.34 (m, 6H), 2.02-1.92 (m, 2H), 1.59-1.51(m, 2H). ESI-MS: $m / z[\mathrm{M}+\mathrm{H}]^{+} 345$. Anal. Calcd for $\mathrm{C}_{19} \mathrm{H}_{24} \mathrm{~N}_{2} \mathrm{O}_{4}$ : C, 66.26; H, 7.02; N, 8.13. Found: C, 66.40; H, 7.11; N, 8.32. 


\subsection{General Procedure for the Preparation of $\mathbf{3 0}$ and $\mathbf{3 p}$}

$70 \% \mathrm{NaH}(0.17 \mathrm{~g}, 4.9 \mathrm{mmol})$ was added portionwise to a solution of $\mathbf{2 a}(1.0 \mathrm{~g}, 4.9 \mathrm{mmol})$ in DMF $(10 \mathrm{~mL})$ at $0 \sim 5{ }^{\circ} \mathrm{C}$. The reaction mixture was warmed to room temperature and stirred for $30 \mathrm{~min}$. After that, iodomethane or 1-bromobutane $(5.9 \mathrm{mmol})$ was added at $0{ }^{\circ} \mathrm{C}$ and stirred for $1 \mathrm{~h}$ at room temperature. The mixture was then poured into cold water $(100 \mathrm{~mL})$ and extracted with ethyl acetate $(3 \times 50 \mathrm{~mL})$. The organic phase was combined, washed with brine $(3 \times 150 \mathrm{~mL})$, dried over $\mathrm{Na}_{2} \mathrm{SO}_{4}$ and concentrated in vacuo. The residue was purified by flash column chromatography on silica gel using petroleum ether/ ethyl acetate $(3: 1, \mathrm{v} / \mathrm{v})$ as eluent to afford $\mathbf{3 0}$ and $\mathbf{3 p}$.

Methyl 2-(1-methyl-1H-indol-3-yl)-2-oxoacetate (3o). Light yellow solid, 76.8\% yield, mp: 73-74 ${ }^{\circ} \mathrm{C}$. ${ }^{1} \mathrm{H}-\mathrm{NMR}\left(\mathrm{CDCl}_{3}\right) \delta 8.51-8.42(\mathrm{~m}, 1 \mathrm{H}), 8.35(\mathrm{~s}, 1 \mathrm{H}), 7.39-7.36(\mathrm{~m}, 3 \mathrm{H}), 3.96(\mathrm{~s}, 3 \mathrm{H}), 3.88(\mathrm{~s}, 3 \mathrm{H})$. ESI-MS: $m / z[\mathrm{M}+\mathrm{H}]^{+}$218. Anal. Calcd for $\mathrm{C}_{12} \mathrm{H}_{11} \mathrm{NO}_{3}$ : C, 66.35; H, 5.10; N, 6.45. Found: C, 66.55; H, $5.20 ; \mathrm{N}, 6.59$.

Methyl 2-(1-butyl-1H-indol-3-yl)-2-oxoacetate (3p). White solid, 80.5\% yield, mp: $81-82{ }^{\circ} \mathrm{C}$. ${ }^{1} \mathrm{H}-\mathrm{NMR}$ $\left(\mathrm{CDCl}_{3}\right) \delta 8.48-8.44(\mathrm{~m}, 1 \mathrm{H}), 8.39(\mathrm{~s}, 1 \mathrm{H}), 7.45-7.38(\mathrm{~m}, 1 \mathrm{H}), 7.37-7.32(\mathrm{~m}, 2 \mathrm{H}), 4.20$ (t, $J=7.5 \mathrm{~Hz}$, 2H), $3.96(\mathrm{~s}, 3 \mathrm{H}), 1.86-1.82(\mathrm{~m}, 2 \mathrm{H}), 1.42-1.38(\mathrm{~m}, 2 \mathrm{H}), 0.98(\mathrm{t}, J=7.5 \mathrm{~Hz}, 3 \mathrm{H})$. ESI-MS: $m / z$ $[\mathrm{M}+\mathrm{H}]^{+}$260. Anal. Calcd for $\mathrm{C}_{15} \mathrm{H}_{17} \mathrm{NO}_{3}: \mathrm{C}, 69.48 ; \mathrm{H}, 6.61 ; \mathrm{N}, 5.40$. Found: $\mathrm{C}, 69.62 ; \mathrm{H}, 6.52 ; \mathrm{N}, 5.65$.

\subsection{General Procedure for the Preparation of $\mathbf{7 a -}-\mathbf{q}$}

A solution of t-BuOK $(94.0 \mathrm{mg}, 0.84 \mathrm{mmol})$ in THF $(5 \mathrm{~mL})$ was added dropwise to a solution of $\mathbf{3 a}-\mathbf{q}$ $(0.36 \mathrm{mmol})$ and 2-(benzo[d]isoxazol-3-yl)acetamide $6(0.28 \mathrm{mmol})$ in dry THF $(10 \mathrm{~mL})$ at $-10 \sim 0{ }^{\circ} \mathrm{C}$. After stirring for $2 \mathrm{~h}$ at room temperature, concentrated hydrochloric acid $(5 \mathrm{~mL})$ was added and the result mixture was stirred for $30 \mathrm{~min}$ at room temperature, then poured into $10 \% \mathrm{NaHCO}_{3}$ aqueous solution $(100 \mathrm{~mL})$ and extracted with ethyl acetate $(3 \times 50 \mathrm{~mL})$. The organic phase was combined and washed with brine $(3 \times 150 \mathrm{~mL})$, dried over $\mathrm{Na}_{2} \mathrm{SO}_{4}$ and concentrated in vacuo. The residue was purified by flash column chromatography on silica gel using dichloromethane/methanol (50:1, v/v) as eluent to afford $7 \mathbf{a}-\mathbf{q}$.

3-(Benzo[d]isoxazol-3-yl)-4-(1H-indol-3-yl)-1H-pyrrole-2,5-dione (7a). Red solid, 44.4\% yield, mp: 227-228 ${ }^{\circ} \mathrm{C} .{ }^{1} \mathrm{H}-\mathrm{NMR}\left(\mathrm{DMSO}-d_{6}\right) \delta 12.14$ (brs, $\left.1 \mathrm{H}\right), 11.44$ (brs, $\left.1 \mathrm{H}\right), 8.23$ (s, 1H), $7.83(\mathrm{~d}, J=8.5 \mathrm{~Hz}$, 1H), 7.69-7.58 (m, 2H), $7.44(\mathrm{~d}, J=8.0 \mathrm{~Hz}, 1 \mathrm{H}), 7.31$ (t, $J=7.5 \mathrm{~Hz}, 1 \mathrm{H}), 7.08-7.04(\mathrm{~m}, 1 \mathrm{H}), 6.72$ (t, $J=8.0 \mathrm{~Hz}, 1 \mathrm{H}), 6.51(\mathrm{~d}, J=8.5 \mathrm{~Hz}, 1 \mathrm{H})$. ESI-MS: $m / z[\mathrm{M}+\mathrm{H}]^{+}$330. Anal. Calcd for $\mathrm{C}_{19} \mathrm{H}_{11} \mathrm{~N}_{3} \mathrm{O}_{3}$ : C, 69.30; H, 3.37; N, 12.76. Found: C, 69.06; H, 3.45; N, 12.64

3-(Benzo[d]isoxazol-3-yl)-4-(5-methoxy-1-(3-morpholinopropyl)-1H-indol-3-yl)-1H-pyrrole-2,5-dione (7b). Saffron yellow solid, 11.6\% yield, mp: $191-193{ }^{\circ} \mathrm{C} .{ }^{1} \mathrm{H}-\mathrm{NMR}\left(\mathrm{CDCl}_{3}\right) \delta 8.27(\mathrm{~s}, 1 \mathrm{H}), 7.97$ (brs, $1 \mathrm{H}), 7.66-7.62(\mathrm{~m}, 2 \mathrm{H}), 7.57(\mathrm{td}, J=8.0,1.5 \mathrm{~Hz}, 1 \mathrm{H}), 7.25-7.23(\mathrm{~m}, 2 \mathrm{H}), 6.76(\mathrm{dd}, J=9.0,2.5 \mathrm{~Hz}$, $1 \mathrm{H}), 5.94(\mathrm{~d}, J=2.5 \mathrm{~Hz}, 1 \mathrm{H}), 4.29(\mathrm{t}, J=6.5 \mathrm{~Hz}, 2 \mathrm{H}), 3.77$ (t, $J=4.5 \mathrm{~Hz}, 4 \mathrm{H}), 3.11(\mathrm{~s}, 3 \mathrm{H}), 2.48-2.42$ $(\mathrm{m}, 4 \mathrm{H}), 2.32(\mathrm{t}, J=6.5 \mathrm{~Hz}, 2 \mathrm{H}), 2.06-2.01(\mathrm{~m}, 2 \mathrm{H})$. ESI-MS: $m / z[\mathrm{M}+\mathrm{H}]^{+}$487. Anal. Calcd for $\mathrm{C}_{27} \mathrm{H}_{26} \mathrm{~N}_{4} \mathrm{O}_{5}$ : C, 66.65; H, 5.39; N, 11.52. Found: C, 66.76; H, 5.47; N, 11.62. 
3-(Benzo[d]isoxazol-3-yl)-4-(5-bromo-1-(3-morpholinopropyl)-1H-indol-3-yl)-1H-pyrrole-2,5-dione (7c). Saffron yellow solid, 21.3\% yield, mp: $180-182{ }^{\circ} \mathrm{C} .{ }^{1} \mathrm{H}-\mathrm{NMR}\left(\mathrm{CDCl}_{3}\right) \delta 8.32(\mathrm{~s}, 1 \mathrm{H}), 7.97$ (brs, $1 \mathrm{H}), 7.68(\mathrm{t}, J=8.5 \mathrm{~Hz}, 2 \mathrm{H}), 7.61(\mathrm{td}, J=8.5,1.5 \mathrm{~Hz}, 1 \mathrm{H}), 7.32(\mathrm{t}, J=8.0 \mathrm{~Hz}, 1 \mathrm{H}), 7.26-7.25(\mathrm{~m}$, $2 \mathrm{H}), 6.81(\mathrm{~s}, 1 \mathrm{H}), 4.29(\mathrm{t}, J=7.0 \mathrm{~Hz}, 2 \mathrm{H}), 3.75(\mathrm{t}, J=4.5 \mathrm{~Hz}, 4 \mathrm{H}), 2.42-2.39(\mathrm{~m}, 4 \mathrm{H}), 2.30$ (t, $J=6.6 \mathrm{~Hz}$, 2H), 2.03-2.01 (m, 2H). ESI-MS: $m / z[\mathrm{M}+\mathrm{H}]^{+}$535. Anal. Calcd for $\mathrm{C}_{26} \mathrm{H}_{23} \mathrm{~N}_{4} \mathrm{O}_{4} \mathrm{Br}: \mathrm{C}, 58.33 ; \mathrm{H}, 4.33$; N, 10.46. Found: C, 58.21; H, 4.49; N, 10.53 .

3-(Benzo[d] isoxazol-3-yl)-4-(6-bromo-1-(3-morpholinopropyl)-1H-indol-3-yl)-1H-pyrrole-2,5-dione (7d). Saffron yellow solid, 12.7\% yield, mp: $226-228{ }^{\circ} \mathrm{C} .{ }^{1} \mathrm{H}-\mathrm{NMR}\left(\mathrm{CDCl}_{3}\right) \delta 8.27(\mathrm{~s}, 1 \mathrm{H}), 7.97$ (brs, 1H), 7.68-7.64 (m, 2H), 7.62 (d, $J=2.0 \mathrm{~Hz}, 1 \mathrm{H}), 7.59$ (td, $J=7.0,1.0 \mathrm{~Hz}, 2 \mathrm{H}), 7.29$ (t, $J=8.0 \mathrm{~Hz}$, $1 \mathrm{H}), 6.99(\mathrm{dd}, J=8.0,2.0 \mathrm{~Hz}, 1 \mathrm{H}), 6.59(\mathrm{~d}, J=8.0 \mathrm{~Hz}, 1 \mathrm{H}), 4.29(\mathrm{t}, J=6.5 \mathrm{~Hz}, 2 \mathrm{H}), 3.79(\mathrm{t}, J=4.5 \mathrm{~Hz}$, $4 \mathrm{H}), 2.47-2.40(\mathrm{~m}, 4 \mathrm{H}), 2.29(\mathrm{t}, J=6.5 \mathrm{~Hz}, 2 \mathrm{H}), 2.05-2.02(\mathrm{~m}, 2 \mathrm{H})$. ESI-MS: $m / z[\mathrm{M}+\mathrm{H}]^{+} 535$. Anal. Calcd for $\mathrm{C}_{26} \mathrm{H}_{23} \mathrm{~N}_{4} \mathrm{O}_{4} \mathrm{Br}$ : C, 58.33; H, 4.33; N, 10.46. Found: C, 58.39; H, 4.51; N, 10.42 .

3-(Benzo[d] isoxazol-3-yl)-4-(6-chloro-1-(3-morpholinopropyl)-1H-indol-3-yl)-1H-pyrrole-2,5-dione (7e). Red solid, 11.5\% yield, mp: 216-218 ${ }^{\circ} \mathrm{C} .{ }^{1} \mathrm{H}-\mathrm{NMR}\left(\mathrm{CDCl}_{3}\right) \delta 8.29(\mathrm{~s}, 1 \mathrm{H}), 7.97(\mathrm{brs}, 1 \mathrm{H}), 7.65$ (t, $J=7.5 \mathrm{~Hz}, 2 \mathrm{H}), 7.59$ (t, $J=8.0 \mathrm{~Hz}, 1 \mathrm{H}), 7.45(\mathrm{~d}, J=1.5 \mathrm{~Hz}, 1 \mathrm{H}), 7.28(\mathrm{t}, J=7.5 \mathrm{~Hz}, 1 \mathrm{H}), 6.85(\mathrm{dd}$, $J=8.5,1.5 \mathrm{~Hz}, 1 \mathrm{H}), 6.64(\mathrm{~d}, J=8.5 \mathrm{~Hz}, 1 \mathrm{H}), 4.29(\mathrm{t}, J=6.5 \mathrm{~Hz}, 2 \mathrm{H}), 3.78(\mathrm{t}, J=4.5 \mathrm{~Hz}, 4 \mathrm{H})$, 2.45-2.41 (m, 4H), $2.29(\mathrm{t}, J=6.5 \mathrm{~Hz}, 2 \mathrm{H}), 2.06-2.02(\mathrm{~m}, 2 \mathrm{H})$. ESI-MS: $m / z[\mathrm{M}+\mathrm{H}]^{+} 491$. Anal. Calcd for $\mathrm{C}_{26} \mathrm{H}_{23} \mathrm{~N}_{4} \mathrm{O}_{4} \mathrm{Cl}$ : C, 63.61; H, 4.72; N, 11.41. Found: C, 63.52; H, 4.64; N, 11.51.

3-(Benzo[d] isoxazol-3-yl)-4-(6-fluoro-1-(3-morpholinopropyl)-1H-indol-3-yl)-1H-pyrrole-2,5-dione (7f). Yellow solid, 29.9\% yield, mp: $219-221{ }^{\circ} \mathrm{C} .{ }^{1} \mathrm{H}-\mathrm{NMR}\left(\mathrm{CDCl}_{3}\right) \delta 8.29(\mathrm{~s}, 1 \mathrm{H}), 8.06(\mathrm{brs}, 1 \mathrm{H})$, $7.66-7.66(\mathrm{~m}, 2 \mathrm{H}), 7.58(\mathrm{t}, J=7.5 \mathrm{~Hz}, 1 \mathrm{H}), 7.29(\mathrm{t}, J=7.5 \mathrm{~Hz}, 1 \mathrm{H}), 7.11(\mathrm{~d}, J=9.5 \mathrm{~Hz}, 1 \mathrm{H})$, 6.68-6.62 (m, 2H), $4.27(\mathrm{t}, J=6.5 \mathrm{~Hz}, 2 \mathrm{H}), 3.77(\mathrm{t}, J=4.5 \mathrm{~Hz}, 4 \mathrm{H}), 2.46-2.41(\mathrm{~m}, 4 \mathrm{H}), 2.31$ (t, $J=6.5 \mathrm{~Hz}, 2 \mathrm{H}), 2.06-2.03(\mathrm{~m}, 2 \mathrm{H})$. ESI-MS: $m / z[\mathrm{M}+\mathrm{H}]^{+}$475. Anal. Calcd for $\mathrm{C}_{26} \mathrm{H}_{23} \mathrm{~N}_{4} \mathrm{O}_{4} \mathrm{~F}: \mathrm{C}$, 65.81; H, 4.89; N, 11.81. Found: C, 65.99; H, 4.75; N, 11.87.

3-(Benzo[d]isoxazol-3-yl)-4-(1-(2-morpholinoethyl)-1H-indol-3-yl)-1H-pyrrole-2,5-dione (7g). Yellow solid, 24.0\% yield, mp: $205-207{ }^{\circ} \mathrm{C} .{ }^{1} \mathrm{H}-\mathrm{NMR}\left(\mathrm{CDCl}_{3}\right) \delta 8.39$ (s, $\left.1 \mathrm{H}\right), 7.79$ (brs, $\left.1 \mathrm{H}\right), 7.57$ (t, $J=7.5 \mathrm{~Hz}$, 2H), $7.35(\mathrm{~d}, J=8.0 \mathrm{~Hz}, 1 \mathrm{H}), 7.25(\mathrm{t}, J=7.5 \mathrm{~Hz}, 1 \mathrm{H}), 7.19(\mathrm{t}, J=7.5 \mathrm{~Hz}, 1 \mathrm{H}), 6.90$ (t, $J=7.5 \mathrm{~Hz}$, $1 \mathrm{H}), 6.73(\mathrm{~d}, J=8.0 \mathrm{~Hz}, 1 \mathrm{H}), 4.31(\mathrm{t}, J=6.5 \mathrm{~Hz}, 2 \mathrm{H}), 3.73(\mathrm{t}, J=7.5 \mathrm{~Hz}, 4 \mathrm{H}), 2.82(\mathrm{t}, J=6.5 \mathrm{~Hz}$, 2H), 2.56-2.42 (m, 4H). ESI-MS: $m / z[\mathrm{M}+\mathrm{H}]^{+}$443. Anal. $\mathrm{C}_{25} \mathrm{H}_{22} \mathrm{~N}_{4} \mathrm{O}_{4}$ : C, 67.86; H, 5.01; N, 12.66 . Found: C, 67.96; H, 5.11; N, 12.85 .

3-(Benzo[d] isoxazol-3-yl)-4-(1-(3-morpholinopropyl)-1H-indol-3-yl)-1H-pyrrole-2,5-dione (7h). Red solid, 38.1\% yield, mp: $197-198{ }^{\circ} \mathrm{C} .{ }^{1} \mathrm{H}-\mathrm{NMR}\left(\mathrm{CDCl}_{3}\right) \delta 8.89$ (brs, $\left.1 \mathrm{H}\right), 8.33$ (s, 1H), 7.66-7.60 (m, 2H), $7.55(\mathrm{td}, J=7.0,1.0 \mathrm{~Hz} 1 \mathrm{H}), 7.37(\mathrm{~d}, J=8.0 \mathrm{~Hz}, 1 \mathrm{H}), 7.24(\mathrm{t}, J=7.5 \mathrm{~Hz}, 1 \mathrm{H}), 7.16(\mathrm{t}, J=7.5 \mathrm{~Hz}$, $1 \mathrm{H}), 6.86(\mathrm{t}, J=7.5 \mathrm{~Hz}, 1 \mathrm{H}), 6.67(\mathrm{~d}, J=8.0 \mathrm{~Hz}, 1 \mathrm{H}), 4.32(\mathrm{t}, J=6.5 \mathrm{~Hz}, 2 \mathrm{H}), 3.79$ (t, $J=4.5 \mathrm{~Hz}$, $4 \mathrm{H}), 2.52-2.42(\mathrm{~m}, 4 \mathrm{H}), 2.37(\mathrm{t}, J=7.0 \mathrm{~Hz}, 2 \mathrm{H}), 2.13-2.05(\mathrm{~m}, 2 \mathrm{H})$. ESI-MS: $m / z[\mathrm{M}+\mathrm{H}]^{+} 457$. Anal. $\mathrm{C}_{26} \mathrm{H}_{24} \mathrm{~N}_{4} \mathrm{O}_{4}: \mathrm{C}, 68.41 ; \mathrm{H}, 5.30 ; \mathrm{N}, 12.27$. Found: C, 68.69; H, 5.25; N, 12.41. 
3-(Benzo[d] isoxazol-3-yl)-4-(1-(4-morpholinobutyl)-1H-indol-3-yl)-1H-pyrrole-2,5-dione (7i). Red solid, 22.6\% yield, mp: 89-91 ${ }^{\circ} \mathrm{C} .{ }^{1} \mathrm{H}-\mathrm{NMR}\left(\mathrm{CDCl}_{3}\right) \delta 8.28(\mathrm{~s}, 1 \mathrm{H}), 8.25(\mathrm{brs}, 1 \mathrm{H}), 7.66-7.62(\mathrm{~m}, 2 \mathrm{H})$, $7.56(\mathrm{t}, J=7.5 \mathrm{~Hz}, 1 \mathrm{H}), 7.35(\mathrm{~d}, J=8.0 \mathrm{~Hz}, 1 \mathrm{H}), 7.24(\mathrm{t}, J=8.0 \mathrm{~Hz}, 1 \mathrm{H}), 7.18(\mathrm{t}, J=7.0 \mathrm{~Hz}, 1 \mathrm{H}), 6.88$ (t, $J=7.5 \mathrm{~Hz}, 1 \mathrm{H}), 6.72(\mathrm{~d}, J=8.0 \mathrm{~Hz}, 1 \mathrm{H}), 4.23(\mathrm{t}, J=6.5 \mathrm{~Hz}, 2 \mathrm{H}), 3.71(\mathrm{t}, J=4.5 \mathrm{~Hz}, 4 \mathrm{H}), 2.45-2.35$ $(\mathrm{m}, 6 \mathrm{H}), 2.01-1.90(\mathrm{~m}, 2 \mathrm{H}), 1.62-1.55(\mathrm{~m}, 2 \mathrm{H})$. ESI-MS: $m / z[\mathrm{M}+\mathrm{H}]^{+}$471. Anal. $\mathrm{C}_{27} \mathrm{H}_{26} \mathrm{~N}_{4} \mathrm{O}_{4}$ : C, 68.92; H, 5.57; N, 11.91. Found: C, 68.75; H, 5.62; N, 11.82 .

3-(1-(3-(1H-Imidazol-1-yl)propyl)-1H-indol-3-yl)-4-(benzo[d]isoxazol-3-yl)-1H-pyrrole-2,5-dione Red solid, 16.1\% yield, mp: 208-210 ${ }^{\circ} \mathrm{C} .{ }^{1} \mathrm{H}-\mathrm{NMR}\left(\mathrm{CDCl}_{3}\right) \delta 8.32$ (brs, 1H), 8.24 (s, 1H), 7.67 (d, $J=8.5 \mathrm{~Hz}, 1 \mathrm{H}), 7.85(\mathrm{~d}, J=8.5 \mathrm{~Hz}, 1 \mathrm{H}), 7.61-7.53(\mathrm{~m}, 2 \mathrm{H}), 7.29(\mathrm{t}, J=7.0 \mathrm{~Hz}, 1 \mathrm{H}), 7.24-7.18$ (m, 2H), $7.17(\mathrm{~s}, 1 \mathrm{H}), 6.98(\mathrm{~s}, 1 \mathrm{H}), 6.94(\mathrm{td}, J=7.0,1.0 \mathrm{~Hz}, 1 \mathrm{H}), 6.81(\mathrm{~d}, J=8.0 \mathrm{~Hz}, 1 \mathrm{H}), 4.20(\mathrm{t}, J=6.5 \mathrm{~Hz}$, $2 \mathrm{H}), 3.99(\mathrm{t}, J=6.5 \mathrm{~Hz}, 2 \mathrm{H}), 2.47-2.40(\mathrm{~m}, 2 \mathrm{H})$. ESI-MS: $m / z[\mathrm{M}+\mathrm{H}]^{+}$438. Anal. $\mathrm{C}_{25} \mathrm{H}_{19} \mathrm{~N}_{5} \mathrm{O}_{3}: \mathrm{C}_{\text {, }}$ 68.64; H, 4.38; N, 16.01. Found: C, 68.81; H, 4.35; N, 16.26 .

3-(1-(4-(1H-Imidazol-1-yl)butyl)-1H-indol-3-yl)-4-(benzo[d]isoxazol-3-yl)-1H-pyrrole-2,5-dione (7k). Red solid, $15.6 \%$ yield, mp: $203-205{ }^{\circ} \mathrm{C} .{ }^{1} \mathrm{H}-\mathrm{NMR}\left(\mathrm{CDCl}_{3}\right) \delta 8.35$ (brs, $\left.1 \mathrm{H}\right), 8.24(\mathrm{~s}, 1 \mathrm{H}), 7.69-7.63$ (m, 2H), $7.57(\mathrm{td}, J=7.0,1.5 \mathrm{~Hz}, 1 \mathrm{H}), 7.47(\mathrm{~s}, 1 \mathrm{H}), 7.29(\mathrm{~d}, J=6.0 \mathrm{~Hz}, 1 \mathrm{H}), 7.25(\mathrm{~d}, J=7.5 \mathrm{~Hz}, 1 \mathrm{H})$, $7.19(\mathrm{t}, J=7.5 \mathrm{~Hz}, 1 \mathrm{H}), 7.08(\mathrm{~s}, 1 \mathrm{H}), 6.92(\mathrm{t}, J=7.5 \mathrm{~Hz}, 1 \mathrm{H}), 6.87(\mathrm{~s}, 1 \mathrm{H}), 6.78(\mathrm{~d}, J=8.0 \mathrm{~Hz}, 1 \mathrm{H})$, $4.21(\mathrm{t}, J=6.5 \mathrm{~Hz}, 2 \mathrm{H}), 3.92(\mathrm{t}, J=6.5 \mathrm{~Hz}, 2 \mathrm{H}), 1.95-1.87(\mathrm{~m}, 2 \mathrm{H}), 1.86-1.80(\mathrm{~m}, 2 \mathrm{H})$. ESI-MS: $m / z$ $[\mathrm{M}+\mathrm{H}]^{+}$452. Anal. $\mathrm{C}_{26} \mathrm{H}_{21} \mathrm{~N}_{5} \mathrm{O}_{3}$ : C, 69.17; H, 4.69; N, 15.51. Found: $\mathrm{C}, 68.96 ; \mathrm{H}, 4.65 ; \mathrm{N}, 15.73$.

3-(1-(3-(1H-1,2,4-Triazol-1-yl)propyl)-1H-indol-3-yl)-4-(benzo[d] isoxazol-3-yl)-1H-pyrrole-2,5-dione (7l). Red solid, $21.3 \%$ yield, mp: $214-216{ }^{\circ} \mathrm{C} .{ }^{1} \mathrm{H}-\mathrm{NMR}$ (DMSO- $\left.d_{6}\right) \delta 11.46$ (brs, $\left.1 \mathrm{H}\right), 8.54(\mathrm{~s}, 1 \mathrm{H})$, $8.28(\mathrm{~s}, 1 \mathrm{H}), 8.01(\mathrm{~s}, 1 \mathrm{H}), 7.81(\mathrm{~d}, J=8.5 \mathrm{~Hz}, 1 \mathrm{H}), 7.66-7.61(\mathrm{~m}, 2 \mathrm{H}), 7.52(\mathrm{~d}, J=8.0 \mathrm{~Hz}, 1 \mathrm{H}), 7.29(\mathrm{t}$, $J=7.5 \mathrm{~Hz}, 1 \mathrm{H}), 7.13(\mathrm{t}, J=7.5 \mathrm{~Hz}, 1 \mathrm{H}), 6.79(\mathrm{t}, J=8.0 \mathrm{~Hz}, 1 \mathrm{H}), 6.57(\mathrm{~d}, J=8.0 \mathrm{~Hz}, 1 \mathrm{H}), 4.36(\mathrm{t}$, $J=6.5 \mathrm{~Hz}, 2 \mathrm{H}), 4.20(\mathrm{t}, J=6.5 \mathrm{~Hz}, 2 \mathrm{H}), 2.36-2.28(\mathrm{~m}, 2 \mathrm{H})$. ESI-MS: $m / z[\mathrm{M}+\mathrm{H}]^{+} 439$. Anal. $\mathrm{C}_{24} \mathrm{H}_{18} \mathrm{~N}_{6} \mathrm{O}_{3}: \mathrm{C}, 65.75 ; \mathrm{H}, 4.14 ; \mathrm{N}, 19.17$. Found: C, 65.58; H, 4.12; N, 19.34.

3-(Benzo[d]isoxazol-3-yl)-4-(1-(3-(piperidin-1-yl)propyl)-1H-indol-3-yl)-1H-pyrrole-2,5-dione (7m). Red solid, $15.6 \%$ yield, mp: $73-75^{\circ} \mathrm{C} .{ }^{1} \mathrm{H}-\mathrm{NMR}\left(\mathrm{CDCl}_{3}\right) \delta 8.32(\mathrm{~s}, 1 \mathrm{H}), 7.64(\mathrm{~d}, J=8.5 \mathrm{~Hz}, 1 \mathrm{H}), 7.59$ $(\mathrm{d}, J=8.0 \mathrm{~Hz}, 1 \mathrm{H}), 7.55(\mathrm{td}, J=8.0,1.0 \mathrm{~Hz}, 1 \mathrm{H}), 7.38(\mathrm{~d}, J=8.5 \mathrm{~Hz}, 1 \mathrm{H}), 7.23(\mathrm{t}, J=8.0 \mathrm{~Hz}, 1 \mathrm{H})$, $7.16(\mathrm{t}, J=8.0 \mathrm{~Hz}, 1 \mathrm{H}), 6.85(\mathrm{t}, J=8.0 \mathrm{~Hz}, 1 \mathrm{H}), 6.67(\mathrm{~d}, J=8.0 \mathrm{~Hz}, 1 \mathrm{H}), 4.31(\mathrm{t}, J=7.0 \mathrm{~Hz}, 2 \mathrm{H})$, 2.55-2.35 (m, 6H), 2.17-2.10 (m, 2H), 1.73-1.61 (m, 4H), 1.52-1.47 (m, 2H). ESI-MS: $m / z[\mathrm{M}+\mathrm{H}]^{+}$ 455. Anal. $\mathrm{C}_{27} \mathrm{H}_{26} \mathrm{~N}_{4} \mathrm{O}_{3}$ : C, 71.35; H, 5.77; N, 12.33. Found: $\mathrm{C}, 71.13 ; \mathrm{H}, 5.63 ; \mathrm{N}, 12.46$.

3-(Benzo[d]isoxazol-3-yl)-4-(1-(3-(pyrrolidin-1-yl)propyl)-1H-indol-3-yl)-1H-pyrrole-2,5-dione (7n). Saffron yellow solid, $20.8 \%$ yield, mp: $171-173{ }^{\circ} \mathrm{C} .{ }^{1} \mathrm{H}-\mathrm{NMR}\left(\mathrm{CDCl}_{3}\right) \delta 8.41(\mathrm{~s}, 1 \mathrm{H}), 7.63(\mathrm{~d}, J=8.5$, $1 \mathrm{H}), 7.59(\mathrm{~d}, J=8.5,1 \mathrm{H}), 7.54(\mathrm{td}, J=8.5,1 \mathrm{H}, 1 \mathrm{H}), 7.36(\mathrm{~d}, J=8.0 \mathrm{~Hz}, 1 \mathrm{H}), 7.22(\mathrm{t}, J=7.5 \mathrm{~Hz}, 1 \mathrm{H})$, $7.15(\mathrm{t}, J=7.5 \mathrm{~Hz}, 1 \mathrm{H}), 6.83(\mathrm{t}, J=7.5 \mathrm{~Hz}, 1 \mathrm{H}), 6.62(\mathrm{~d}, J=8.5 \mathrm{~Hz}, 1 \mathrm{H}), 4.32(\mathrm{t}, J=7.0 \mathrm{~Hz}, 2 \mathrm{H})$, 2.65-2.55 (m, 6H), 2.25-2.15 (m, 2H), 1.89-1.83 (m, 4H). ESI-MS: $m / z[\mathrm{M}+\mathrm{H}]^{+} 441$. Anal. $\mathrm{C}_{26} \mathrm{H}_{24} \mathrm{~N}_{4} \mathrm{O}_{3}$ : C, 70.89; H, 5.49; N, 12.72. Found: C, 70.68; H, 5.34; N, 12.97 . 
3-(Benzo[d]isoxazol-3-yl)-4-(1-methyl-1H-indol-3-yl)-1H-pyrrole-2,5-dione (7o). Red solid, 27.8\% yield, mp: $221-222{ }^{\circ} \mathrm{C} .{ }^{1} \mathrm{H}-\mathrm{NMR}\left(\mathrm{CDCl}_{3}\right) \delta 8.24$ (s, $\left.1 \mathrm{H}\right), 7.81$ (brs, $\left.1 \mathrm{H}\right), 7.65(\mathrm{~d}, J=9.5 \mathrm{~Hz}, 2 \mathrm{H}), 7.57$ $(\mathrm{t}, J=8.0 \mathrm{~Hz}, 1 \mathrm{H}), 7.32(\mathrm{~d}, J=8.5 \mathrm{~Hz}, 1 \mathrm{H}), 7.19(\mathrm{t}, J=8.0 \mathrm{~Hz}, 1 \mathrm{H}), 6.97(\mathrm{t}, J=8.0 \mathrm{~Hz}, 1 \mathrm{H}), 6.88(\mathrm{t}$, $J=7.5 \mathrm{~Hz}, 1 \mathrm{H}), 6.65(\mathrm{~d}, J=8.5 \mathrm{~Hz}, 1 \mathrm{H}), 3.90(\mathrm{~s}, 3 \mathrm{H})$. ESI-MS: $m / z[\mathrm{M}+\mathrm{H}]^{+}$344. Anal. $\mathrm{C}_{20} \mathrm{H}_{13} \mathrm{~N}_{3} \mathrm{O}_{3}$ : C, 69.96; H, 3.82; N, 12.24. Found: C, 70.11; H, 3.77; N, 12.05.

3-(Benzo[d]isoxazol-3-yl)-4-(1-butyl-1H-indol-3-yl)-1H-pyrrole-2,5-dione(7p). Saffron yellow solid, $35.2 \%$ yield, mp: ${ }^{180}-182{ }^{\circ} \mathrm{C} .{ }^{1} \mathrm{H}-\mathrm{NMR}\left(\mathrm{CDCl}_{3}\right) \delta 8.25(\mathrm{~s}, 1 \mathrm{H}), 7.82(\mathrm{brs}, 1 \mathrm{H}), 7.65(\mathrm{~d}, J=8.5,1 \mathrm{H})$, $7.61(\mathrm{~d}, J=8.5,1 \mathrm{H}), 7.56(\mathrm{t}, J=8.0 \mathrm{~Hz}, 1 \mathrm{H}), 7.34(\mathrm{~d}, J=8.0 \mathrm{~Hz}, 1 \mathrm{H}), 7.24(\mathrm{t}, J=7.5 \mathrm{~Hz}, 1 \mathrm{H}), 7.18$ $(\mathrm{t}, J=7.5 \mathrm{~Hz}, 1 \mathrm{H}), 6.89$ (t, $J=7.5 \mathrm{~Hz}, 1 \mathrm{H}), 6.75(\mathrm{~d}, J=7.5 \mathrm{~Hz}, 1 \mathrm{H}), 4.22(\mathrm{t}, J=7.5,2 \mathrm{H}), 1.95-1.83$ $(\mathrm{m}, 2 \mathrm{H}), 1.42-1.37(\mathrm{~m}, 2 \mathrm{H}), 0.98(\mathrm{t}, J=7.5 \mathrm{~Hz}, 3 \mathrm{H})$. ESI-MS: $m / z[\mathrm{M}+\mathrm{H}]^{+}$386. Anal. $\mathrm{C}_{23} \mathrm{H}_{19} \mathrm{~N}_{3} \mathrm{O}_{3}$ : C, 71.67; H, 4.97; N, 10.90. Found: C, 71.55; H, 4.84; N, 11.03.

3-(Benzo[d]isoxazol-3-yl)-4-(1-(3-hydroxypropyl)-1H-indol-3-yl)-1H-pyrrole-2,5-dione (7q). Yellow solid, 10.0\% yield, mp: 219-220 ${ }^{\circ} \mathrm{C} .{ }^{1} \mathrm{H}-\mathrm{NMR}\left(\mathrm{CDCl}_{3}\right) \delta 8.29(\mathrm{~s}, 1 \mathrm{H}), 7.64(\mathrm{t}, J=8.0 \mathrm{~Hz}, 2 \mathrm{H}), 7.57$ $(\mathrm{t}, J=7.5 \mathrm{~Hz}, 1 \mathrm{H}), 7.40(\mathrm{~d}, J=8.5 \mathrm{~Hz}, 1 \mathrm{H}), 7.24(\mathrm{t}, J=8.0 \mathrm{~Hz}, 1 \mathrm{H}), 7.19(\mathrm{t}, J=8.0 \mathrm{~Hz}, 1 \mathrm{H}), 6.91$ (t, $J=7.5 \mathrm{~Hz}, 1 \mathrm{H}), 6.79(\mathrm{~d}, J=7.5 \mathrm{~Hz}, 1 \mathrm{H}), 4.39(\mathrm{t}, J=7.0 \mathrm{~Hz}, 2 \mathrm{H}), 3.67$ (t, $J=7.0 \mathrm{~Hz}, 2 \mathrm{H}), 2.17-2.10$ (m, 2H). ESI-MS: $m / z[\mathrm{M}+\mathrm{H}]^{+}$388. Anal. $\mathrm{C}_{22} \mathrm{H}_{17} \mathrm{~N}_{3} \mathrm{O}_{4}$ : C, 68.21; H, 4.42; N, 10.85. Found: C, 68.07; $\mathrm{H}, 4.51 ; \mathrm{N}, 11.09$.

\subsection{Biological Activity Assay}

\subsubsection{Kinase Assay}

Human kinome, consisting of 518 kinases, is classified into CMGC, AGC, TK, TKL, CAMK, STE and other 7 subfamilies, according to the DNA sequence and evolution. GSK3 $\beta$ belongs to CMGC family. Here, the other family members were used to evaluate the selectivity of GSK3 $\beta$ inhibitors, including PKC-epsilon (AGC family), JAK2 (TK family), Braf (TKL family), DRAK2 (CAMK family) and IKK $\beta$ (other family).The recombinant GST-GSK-3ßprotein was expressed in Escherichia coli strain BL21-Codon Plus (DE3), purified by GSTrap affinity chromatography, and cleaved by thrombin. The GSK-3 $\beta$ kinase assay was carried out with the Z'-LYTETM Kinase Assay kit Ser/Thr 9 Peptide substrate (Invitrogen, Grand, NY, USA) in $10 \mu \mathrm{L}$ reaction volume containing $50 \mathrm{nM}$ enzyme, $30 \mu \mathrm{M}$ ATP and $2 \mu \mathrm{M}$ substrate peptide. Drak2 Proteins were presented by professor Jiang-ping Wu (Laboratory of Immunology, Research Centre, CHUM, Notre Dame Hospital, Pavilion DeSève). The Drak2 kinase reaction was performed in a final assay volume of $3.4 \mu \mathrm{L}$ using the ADP-GLO Kinase Assay Kit (Promega, Madison, WI, USA), according the ADP-GLO protocol and read on an EnVision plate reader. The recombinant PKC-epsilon, IKK $\beta$, and JAK2 with N-terminal His-tag were expressed using baculovirus expression system and purified with Ni-Beads. BRAF protein was from Carna Biosciences, Inc. (Kobe Port Island, Japan). And the related kinase reactions were performed in a final assay volume of $10 \mu \mathrm{L}$ using the related HTRF Assay Kit (Cisbio, Codolet, France). Reactions were according the HTRF protocol and read on an EnVision plate reader. All reactions were carried out in triplicate. $\mathrm{IC}_{50}$ values (concentration at which a $50 \%$ of enzyme inhibition is shown) were derived from a nonlinear regression model (curvefit) based on sigmoidal dose response curve (variable slope) and 
computed using Graphpad Prism version 5.02, (Graphpad Software, La Jolla, CA, USA). Data were expressed as mean $\pm \mathrm{SE}$.

\subsubsection{Cell Culture and Western Blotting}

SH-SY5Y human neuroblastoma cells were obtained from the American Type Culture Collection (ATCC, Manassas, VA, USA). Cells were cultured in 1:1 DMEM:Ham's F12 containing 10\% (v/v) fetal bovine serum (HyClone, Logan, UT, USA), 1\% penicillin, and 1\% streptomycin at a humidified atmosphere with $5 \% \mathrm{CO}_{2}$. The medium was changed every 2 days. For experiments, cells were and grown in 12-well plates until $\sim 80 \%$ confluence, serum-deprived for 12 hours, incubated with GSK-3 $\beta$ inhibitors for 1 hour and $A \beta_{25-35}$ (amyloid beta peptide 25-35, Sigma, St. Louis, MO, USA) for another 6 hours. Cells were rinsed twice with ice-cold PBS and lysed with $1 \times$ SDS loading buffer. Samples were electrophoresed on 10\% SDS-polyacrylamide gels, and transferred onto PVDF membranes. The membranes were blocked for $1 \mathrm{~h}$ with $5 \%$ (w/v) milk, incubated with rabbit anti-Tau [pS396] phosopho-specific antibody (Abcam, Cambridge, UK) for $2 \mathrm{~h}$ and the anti-rabbit secondary antibody for $1 \mathrm{~h}$. Antigen-antibody complexes were detected by the ECL Kit.

\section{Conclusions}

In conclusion, a series of novel 3-benzisoxazolyl-4-indolyl-maleimides were synthesized and identified as potent and selective GSK-3 $\beta$ inhibitors. Among them, compound $7 \mathbf{j}$ was the most promising GSK-3 $\beta$ inhibitor, with an $\mathrm{IC}_{50}$ of $0.73 \mathrm{nM}$, which was about 140 -fold more potent than staurosporine. Futher cell-based functional assays showed that all selected compounds such as 7c, 7f, $\mathbf{7 j}-\mathbf{l}$ and $\mathbf{7 0}-\mathbf{q}$ could obviously reduce Tau phosphorylation at $100 \mathrm{nM}$ by inhibiting GSK-3 $\beta$. Preliminary SAR and molecular modeling studies provided further insights into interactions between GSK-3 $\beta$ and its inhibitors. The results are useful for the design of novel and selective GSK-3 $\beta$ inhibitors. Future progress on related series will be reported in due course.

\section{Acknowledgments}

We gratefully acknowledge the financial support from the Natural Science Foundation of China (21176223) and the National Natural Science Foundation of Zhejiang (Y407306).

\section{Conflict of Interest}

The authors declare no conflict of interest.

\section{References}

1. Embi, N.; Rylatt, D.B.; Cohen, P. Glycogen synthase-3 from rabbit skeletal muscle separation from cyclic-AMP-dependent protein kinase and phosphorylase kinase. Eur. J. Biochem. 1980, 107, 519-527.

2. Harwood, A.J. Regulation of GSK-3: A cellular multiprocessor. Cell 2001, 105, 821-824.

3. Yao, H.; Shaw, P.; Wrong, C.; Wan, D.C. Expression of glycogen synthase kinase-3 isoforms in mouse tissues and their transcription in the brain. J. Chem. Neuroanat. 2002, 23, 291-297. 
4. Woodgett, J.R. Molecular cloning and expression of glycogen synthase kinase-3/factor A. EMBO J. 1990, 9, 2431-2438.

5. Eldar-Finkelman, H. Glycogen synthase kinase 3: An emerging therapeutic target. Trends Mol. Med. 2002, 8, 126-132.

6. Doble, B.W.; Woodgett, J.R. GSK-3: Tricks of the trade for a multi-tasking kinase. J. Cell. Sci. 2003, 116, 1175-1186.

7. Jope, R.S.; Yuskaitis, C.J.; Beurel, E. Glycogen Synthase Kinase-3 (GSK3): Inflammation, Diseases, and Therapeutics. Neurochem. Res. 2007, 32, 577-595.

8. Frame, S.; Cohen, P. GSK3 takes centre stage more than 20 years after its discovery. Biochem. J. 2001, 359, 1-16.

9. Kim, L.; Kimmel, A.R. GSK3, a master switch regulating cell-fate specification and tumorigenesis. Curr. Opin. Genet. Dev. 2000, 10, 508-514.

10. Wagman, A.S.; Nuss, J.M. Current therapies and emerging targets for the treatment of diabetes. Curr. Pharm. Des. 2001, 7, 417-450.

11. Cohen, P. The role of protein phosphorylation in human health and disease. Eur. J. Biochem. 2001, 268, 5001-5010.

12. Sasaki, C.; Hayashi, T.; Zhang, W.R.; Warita, H.; Manabe, Y.; Sakai, K.; Abe, K. Different expression of glycogen synthase kinase- $3 \beta$ between young and old rat brains after transient middle cerebral artery occlusion. Neurol. Res. 2001, 23, 588-592.

13. Castro, A.; Martinez, A. Inhibition of tau phosphorylation: A new therapeutic strategy for the treatment of Alzheimer's disease and other neurodegenerative disorders. Exp. Opin. Ther. Pat. 2000, 10, 1519-1527.

14. Bertrand, J.A.; Thieffine, S.; Vulpetti1, A.; Cristiani, C.; Valsasina, B.; Knapp, S. Kalisz, H.M.; Flocco, M. Structural Characterization of the GSK-3 $\beta$ Active Site Using Selective and Non-selective ATP-mimetic Inhibitors. J. Mol. Biol. 2003, 333, 393-407.

15. Hers, I.; Tavare, J.M.; Denton, R.M. The protein kinase C inhibitors bisindolylmaleimide I (GF 109203x) and IX (Ro 31-8220) are potent inhibitors of glycogen synthase kinase-3 activity. FEBS Lett. 1999, 460, 433-436.

16. Zhang, H.-C.; White, K.B.; Ye, H.; McComsey, D.F.; Derian, C.K.; Addo, M.F.; Andrade-Gordon, P.; Eckardt, A.J.; Conway, B.R.; Westover, L.; et al. Macrocyclic bisindolylmaleimides as inhibitors of protein kinase $\mathrm{C}$ and glycogen synthase kinase-3. Bioorg. Med. Chem. Lett. 2003, 13, 3049-3053.

17. Gani, O.A.; Engh, R.A. Protein kinase inhibition of clinically important staurosporine analogues. Nat. Prod. Rep. 2010, 27, 489-498.

18. Pajak, B.; Orzechowska, S.; Gajkowska, B.; Orzechowski, A. Bisindolylmaleimides in anti-cancer therapy-more than PKC inhibitors. Adv. Med. Sci. 2008, 5321-5331.

19. Engler, T.A.; Henry, J.R.; Malhotra, S.; Cunningham, B.; Furness, K.; Brozinick, J.; Burkholder, T.P.; Clay, M.P.; Clayton, J.; Diefenbacher, C.; et al. Substituted 3-Imidazo[1,2a]pyridin-3-yl-4-(1,2,3,4-tetrahydro-[1,4]diazepino-[6,7,1-hi]indol-7- yl) pyrrole-2,5-diones as Highly Selective and Potent Inhibitors of Glycogen Synthase Kinase-3. J. Med. Chem. 2004, 47, 3934-3937. 
20. Ye, Q.; Xu, G.; Lv, D.; Cheng, Z.; Li, J.; Hu, Y. Synthesis and biological evaluation of novel

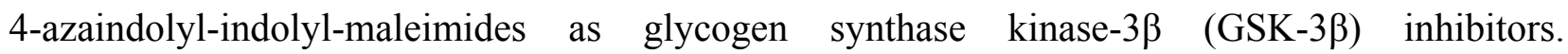
Bioorg. Med. Chem. 2009, 17, 4302-4312.

21. Gaisina, I.N.; Gallier, F.; Ougolkov, A.V.; Kim, K.H.; Kurome, T.; Guo, S.; Holzle, D.; Luchini, D.N.; Blond, S.Y.; Billadeau, D.D.; et al. From a Natural Product Lead to the Identification of Potent and Selective Benzofuran-3- yl-(indol-3-yl)maleimides as Glycogen Synthase Kinase $3 \beta$ Inhibitors That Suppress Proliferation and Survival of Pancreatic Cancer Cells. J. Med. Chem. 2009, 52, 1853-1863.

22. Uno, H.; Kurokawa, M.; Nishimura, H. Studies on 3-substituted 1, 2-benzisoxazole derivatives. II. The catalytic reductions of 1,2-benzisoxazole-3-acetamide oxime and related compounds. Chem. Pharm. Bull. 1976, 24, 632-643.

23. Gong, E.J.; Park, H.R.; Kim, M.E.; Piao, S.; Lee, E.; Jo, D.G.; Chung, H.Y.; Ha, N.C.; Mattson, M.P.; Lee, J. Morin attenuates tau hyperphosphorylation by inhibiting GSK3 $\beta$. Neurobiol. Dis. 2011, 24, 223-230.

24. Sun, Z.K.; Yang, H.Q.; Pan, J.; Zhen, H.; Wang, Z.Q.; Chen, S.D.; Ding, J.Q. Protective effects of erythropoietin on tau phosphorylation induced by $\beta$-amyloid. J. Neurosci. Res. 2008, 86, 3018-3027.

25. Gong, L.; Hirschfeld, D.; Tan, Y.C.; Hogg, J.H.; Peltz, G.; Avnur, Z.; Dunten, P. Discovery of potent and bioavailable GSK-3 $\beta$ inhibitors. Bioorg. Med. Chem. Lett. 2010, 20, 1693-1696.

26. Liu, X.H.; Pan, L.; Ma, Y.; Weng, J.Q.; Tan, C.X.; Li, Y.H.; Shi, Y.X.; Li, B.J.; Li, Z.M.; Zhang, Y.G. Design, Synthesis, Biological Activities, and 3D-QSAR of New N,N'Diacylhydrazines Containing 2-(2,4-dichlorophenoxy)propane Moiety. Chem. Biol. Drug Des. 2011, 78, 689-694.

27. Liu, X.H.; Pan, L.; Tan, C.X.; Weng, J.Q.; Wang, B.L.; Li, Z.M. Synthesis, crystal structure, bioactivity and DFT calculation of new oxime ester derivatives containing cyclopropane moiety. Pestic. Biochem. Physiol. 2011, 101, 143-147.

28. Liu, X.H.; Tan, C.X.; Weng, J.Q. Synthesis, Dimeric Crystal Structure, and Fungicidal Activity of 1-(4-Methylphenyl)-2-(5-((3,5-Dimethyl-1H-Pyrazol-1-yl)methyl)-4-Phenyl-4H-1,2,4-Trizol3-ylthio)Ethanone. Phosphorus Sulfur Silicon Relat. Elem. 2011, 186, 558-564.

29. Liu, X.H.; Pan, L.; Weng, J.Q.; Tan, C.X.; Li, Y.H.; Wang, B.L.; Li, Z.M. Synthesis, structure, and biological activity of novel (oxdi/tri)azoles derivatives containing 1,2,3-thiadiazole or methyl moiety. Mol. Divers. 2012, 16, 251-260.

30. Tan, C.X.; Shi, Y.X.; Weng, J.Q.; Liu, X.H.; Zhao, W.G. Li, B.J. Synthesis and Antifungal Activity of Novel 1,2,4-Triazole Derivatives Containing 1,2,3-Thiadiazole Moiety. J. Heterocycl. Chem. 2013, doi:10.1002/jhet.1656.

31. Liu, X.H.; Weng, J.Q.; Wang, B.L.; Li, Y.H.; Tan, C.X.; Li, Z.M. Microwave-assisted Synthesis and Biological Activity Study of Novel Fluorinated 1,2,4-Triazole Derivatives. Res. Chem. Intermed. 2013, doi:10.1007/s11164-013-1113-4.

32. Tan, C.X.; Shi, Y.X.; Weng, J.Q.; Liu, X.H.; Li, B.J.; Zhao, W.G. Synthesis and Antifungal Activity of 1,2,4-triazole Derivatives Containing Cyclopropane Moiety. Lett. Drug Des. Discov. 2012, 9, 431-435. 
33. Liu, X.H.; Weng, J.Q.; Tan, C.X. Synthesis, Crystal Structure and Fungicidal Activity of 5-(4-cyclopropyl-5-((3-fluorobenzyl)thio)-4H-1,2,4-triazol-3-yl)-4-methyl-1,2,3-thiadiazole. J. Chem. 2013, 2013, 306361.

34. Weng, J.Q.; Wang, L.; Liu, X.H. Synthesis, Crystal Structure and Herbicidal Activity of a 1,2,4-triazol-5(4H)-one Derivative. J. Chem. Soc. Pakistan 2012, 34, 1248-1252.

35. Liu, X.H.; Zhao, W.G.; Wang, B.L.; Li, Z.M. Synthesis, Bioactivity and DFT Structure-Activity Relationship Study of Novel 1,2,3-Thiadiazole Derivatives. Res. Chem. Intermed. 2012, 38, 1999-2008.

36. Tong, J.Y.; Shi, Y.X.; Liu, X.H.; Sun, N.B.; Li, B.J. Synthesis and Fungicidal Activity of 1,2,4-Triazole Derivatives Containing 2-Fluorophenyl Moiety. Chin. J. Org. Chem. 2012, 32, 2373-2377.

37. Tong, J.Y.; Wu, H.K.; Sun, N.B.; Liu, X.H. Synthesis, Crystal Structure and Biological Activity of a New 1,2,4-Triazole Derivative. Chin. J. Struct. Chem. 2013, 32, 607-611.

38. Sun, N.B.; Liu, X.H.; Weng, J.Q.; Tan, C.X. An Unexpected Product N-(3-((2-fluorobenzyl)thio)5-methyl-4H- 1,2,4-triazol-4-yl)acetimidamide: Synthesis and Structure Analysis. J. Chem. Soc. Pakistan 2013, 35, 499-502.

39. Cui, C.; Wang, Z.P.; Du, X.j.; Wang, L.Z.; Yu, S.J.; Liu, X.H.; Li, Z.M.; Zhao, W.G. Synthesis and Antiviral Activity of Hydrogenated Ferulic Acid Derivatives. J. Chem. 2013, 2013, 269434.

40. Wu, R.; Zhu, C.; Du, X.J.; Xiong, L.X.; Yu, S.J.; Liu, X.H.; Li, Z.M.; Zhao, W.G. Synthesis, crystal structure and larvicidal activity of novel diamide derivatives against Culex. pipiens. Chem. Cent. J. 2012, 9, 99.

Sample Availability: Samples of the compounds are available from the authors.

(C) 2013 by the authors; licensee MDPI, Basel, Switzerland. This article is an open access article distributed under the terms and conditions of the Creative Commons Attribution license (http://creativecommons.org/licenses/by/3.0/). 